V. Petoukhov $\cdot$ A. Ganopolski $\cdot$ V. Brovkin

M. Claussen · A. Eliseev · C. Kubatzki · S. Rahmstorf

\title{
CLIMBER-2: a climate system model of intermediate complexity. Part I: model description and performance for present climate
}

Received: 12 January 1998 / Accepted: 2 July 1999

\begin{abstract}
A 2.5-dimensional climate system model of intermediate complexity CLIMBER-2 and its performance for present climate conditions are presented. The model consists of modules describing atmosphere, ocean, sea ice, land surface processes, terrestrial vegetation cover, and global carbon cycle. The modules interact through the fluxes of momentum, energy, water and carbon. The model has a coarse spatial resolution, nevertheless capturing the major features of the Earth's geography. The model describes temporal variability of the system on seasonal and longer time scales. Due to the fact that the model does not employ flux adjustments and has a fast turnaround time, it can be used to study climates significantly different from the present one and to perform long-term (multimillennia) simulations. The comparison of the model results with present climate data show that the model successfully describes the seasonal variability of a large set of characteristics of the climate system, including radiative balance, temperature, precipitation, ocean circulation and cryosphere.
\end{abstract}

\section{Introduction}

Marked progress achieved during the past decades in modeling the separate elements of the climate system (atmosphere, ocean, cryosphere, land, and biosphere)

\footnotetext{
V. Petoukhov · A. Ganopolski $(\bowtie) \cdot$ V. Brovkin · M. Claussen

C. Kubatzki $\cdot$ S. Rahmstorf

Potsdam Institute for Climate Impact Research,

P O. Box 601203, D-14412 Potsdam, Germany

E-mail: andrey@pik-potsdam.de

V. Petoukhov - A. Eliseev

A.M. Obukhov Institute for Atmospheric Physics,

Pyzhevsky 3, 109017 Moscow, Russia

M. Claussen

Institut für Meteorologie, Freie Universität,

Berlin, Carl-Heinrich Becker Weg 6-10,

D-12165, Berlin, Germany
}

has taught us that all elements and processes within the climate system are closely interlinked. This stimulates attempts to put all separate pieces together, first in the form of fully fledged climate models (coupled climate GCMs), and eventually as climate system models. While climate models deal with the physical processes only, climate system models take into account also biological and geochemical processes. Among the crucial questions which can only be addressed with climate system models is the interaction between geosphere and biosphere. It has been shown in many publications (see e.g., de Noblet et al. 1996; Claussen and Gayler 1997; Ganopolski et al. 1998b) that biogeophysical feedbacks can strongly amplify and modify the climatic changes caused by changes in the orbital parameters of the Earth. The biogeochemical feedbacks, e.g., interaction between climatic changes and global carbon cycle (Melillo et al. 1993; Sarmiento and Le Quere 1996; Cao and Woodward 1998) are also important.

There are two basic classes of climate system models: simplified and comprehensive. Simplified and computationally efficient models of the climate system are used for a variety of applications, in particular paleostudies (e.g., Harvey 1989; Berger et al. 1992) and future global change projections (Alcamo et al. 1994; Xiao et al. 1997). These models are highly spatially aggregated (box, one- or two-dimensional) and describe a limited number of processes and variables. The applicability of this class of model is limited by the lack of many important processes and feedbacks operating in the real world. Comprehensive models are based on climate GCMs and sophisticated models of other elements of the climate system. They have a spatial resolution of a few hundred kilometers and describe a large set of processes and feedbacks (e.g., Foley et al. 1998). The major limitation in the application of comprehensive models arises from their high computational cost. To obtain an equilibrium state of the system, it is necessary to integrate a model for at least a thousand years, the time scale imposed by the ocean. Another problem is the necessity of flux adjustments to obtain a realistic present climate 
state (see e.g., Houghton et al. 1996). The use of flux adjustments imposes strong limitations on the applicability of the models to climate states different from the present one.

There is an obvious gap between simple and comprehensive models. We present an attempt to develop a climate system model of intermediate complexity which fills this gap. The model describes a large set of processes and feedbacks in the climate system, comparable with that of comprehensive models, but due to low spatial resolution and simplified governing equations, our model has a fast turnaround time. This makes it suitable for long-term simulations of climate system dynamics, particularly for paleoclimate studies. Here we present a general description of the model and a comparison of model results with observed climate data.

\section{General structure of CLIMBER-2}

CLIMBER-2 (CLIMate-BiosphERe model) is a low-resolution climate system model designed for simulation of large-scale processes on time scales from seasonal to millennia and longer. CLIMBER-2 could be classified as a model of intermediate complexity, placed between simple models, usually 1- or 2-D, on one hand, and 3-D climate GCMs on the other. It presently consists of the following modules: atmosphere, ocean, sea ice and terrestrial vegetation. These are linked through the fluxes of energy, momentum, water and other substances via an atmosphere-surface interface module. The atmosphere module is a crucial element of climate system models, which primarily determines the characteristics of the model and its field of applicability. Simple models usually employ 1- or 2-D energy balance or statistical-dynamical atmosphere models, while complex models are based on atmospheric GCMs. The atmosphere module of CLIMBER-2 is a 2.5dimensional statistical-dynamical model which has many features in common with more sophisticated models (GCMs). Since the present version of the atmospheric model has not been described elsewhere, we present this part of CLIMBER-2 in detail, while the other modules are described only briefly.

The CLIMBER-2 model has a low spatial resolution which only resolves individual continents (subcontinents) and ocean basins (Fig. 1). Latitudinal resolutions is the same for all modules $\left(10^{\circ}\right)$. In the longitudinal direction the Earth is represented by seven equal sectors (roughly $51^{\circ}$ longitude) in the atmosphere and land modules. The ocean model is a zonally averaged multibasin model, which in longitudinal direction resolves only three ocean basins

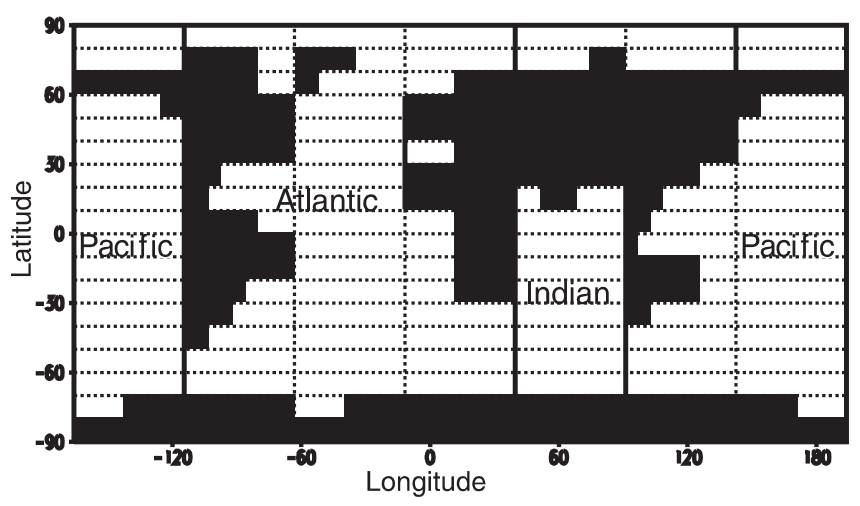

Fig. 1 Representation of the Earth's geography in the model. Dashed lines show atmospheric grid, solid lines separate ocean basins
(Atlantic, Indian, Pacific). Each ocean grid cell communicates with either one, two or three atmosphere grid cells, depending on the width of the ocean basin. Very schematic orography and bathymetry are prescribed in the model, to represent the Tibetan plateau, the high Antarctic elevation and the presence of the Greenland-Scotland sill in the Atlantic ocean.

\section{Atmosphere module}

The atmospheric module of CLIMBER-2 originates from the class of statistical-dynamical models (see e.g., Saltzman 1978). The statistical-dynamical approach is based on the assumption that the basic features of the long-term evolution of the atmosphere can be expressed in terms of large-scale long-term fields of the main atmospheric variables $\left(\hat{y}_{i}=\hat{u}, \hat{v}, \hat{w}, \hat{T}\right.$, etc.) with characteristic spatial scales of about $1000 \mathrm{~km}$ and more, and seasonal temporal scale, and ensembles of synoptic-scale eddies and waves represented by their averaged statistical characteristics $\left.\widehat{\left(y_{i}^{\prime} y_{j}^{\prime}\right.}\right)$. The phenomenological basis for this approach is:

1. The existence of a pronounced stable minimum at a time scale from 10 days to a few months in power spectra of the main atmospheric variables, which allows us to distinguish between synoptic-scale, convective and "turbulent" processes on one hand, and slower processes on the other hand (Van der Hoven 1957; Vinnichenko 1970; Mitchell 1976).

2. The existence of a characteristic horizontal spatial correlation radius of the order of $1000-3000 \mathrm{~km}$ for the synoptic component (Hasselmann 1976; Lemke 1977) which is the upper limit for the horizontal spatial correlation radii of the fast processes mentioned.

The equations for $\hat{y}_{i}$ and $\widehat{y_{i}^{\prime} y_{j}^{\prime}}$ are derived from a set of primitive hydrothermodynamic equations. An important assumption made when deducing the governing equations is that the atmosphere on the spatial/temporal scales mentioned has a universal vertical structure of temperature $\hat{T}$ and humidity $\hat{q}$ fields. This assumption is supported by the results of a large number of empirical studies (see, e.g., Wallace and Hobbs 1977; Oort and Rasmusson 1971). The use of a universal vertical structure allows us to reduce the 3-dimensional description of the atmosphere to a set of 2-dimensional, vertically averaged prognostic equations for temperature and water vapor, and to reconstruct the 3-dimensional structure of these characteristics for computation of horizontal transport and radiative fluxes. All the other hydrothermodynamical fields $\hat{y}_{i}$ are diagnostically expressed in the model in terms of $T, q$ and synoptic moments (hereafter the hats over large-scale long-term variables are dropped). Due to this fact the model has no specific vertical resolution. The number of levels (10) used for computation of wind velocity, energy and water transport, and the number of levels (16) for calculation of radiative fluxes are different and are chosen to provide proper numerical accuracy.

\subsection{Vertical structure of the atmosphere}

The basic elements of the vertical atmospheric structure are shown in Fig. 2. The vertical temperature profile is assumed to be linear in the troposphere, while in the stratosphere temperature is constant with height:

$T(z)= \begin{cases}T_{a}-\Gamma\left(z-z_{s}\right), & \text { if } z_{s}<z<H_{t} \\ T_{a}-\Gamma\left(H_{t}-z_{s}\right), & \text { if } H_{t} \leq z \leq H_{a}\end{cases}$

where $z_{s}$ is the underlying surface elevation, $H_{t}$ and $H_{a}$ are the tropopause and atmosphere height respectively, and $\Gamma$ is the atmospheric lapse rate. $T_{a}$ is a temperature which would occur near the surface if the lapse rate did not change within the planetary boundary layer (PBL). In reality the vertical profile of temperature can deviate significantly from that given by Eq. (1) in a relatively thin (hundreds of meters) surface layer (SL). Therefore, we com- 


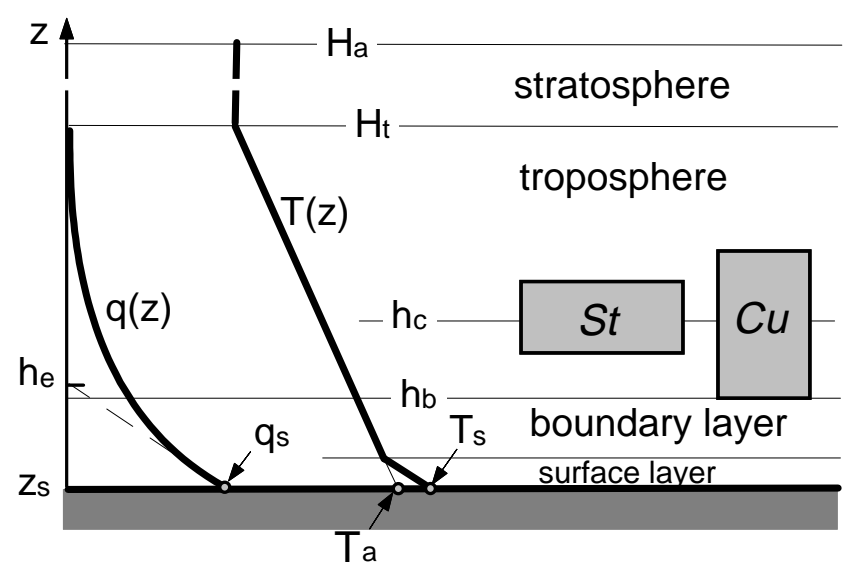

Fig. 2 Parametrization of the vertical structure of the atmosphere in the model

pute the near-surface temperature $T_{s}$ using boundary layer theory (e.g., Hansen et al. 1983). The temperature $T_{s}$ is used for computing surface fluxes. In all vertically integrated equations, as well as in the dynamical equations, we neglect the deviation of temperature in the PBL from the profile described by Eq. (1).

The lapse rate $\Gamma$ in the troposphere is computed in the model using the formula based on the theoretical approach of Mokhov an Petoukhov (1978) and fitted to the empirical data of Gulev et al. (1991)

$\Gamma=\Gamma_{0}+\Gamma_{1}\left(T_{a}-T_{*}\right)\left(1-a_{q} q_{s}^{2}\right)-\Gamma_{2} n_{c}$,

where $q_{s}$ is the surface air specific humidity, $n_{c}$ is the cumulus cloud amount, and $\Gamma_{0}, \Gamma_{1}, \Gamma_{2}, a_{q}, T_{*}$, are model parameters listed (together with other empirical parameters appearing below) in Table 1. The troposphere height is parametrized as:

$H_{t}=C_{t} \frac{T_{a}}{\Gamma}\left[1-\left(\frac{D}{1+D}\right)^{1 / 4}\right]$,

where $D$ is the integral transmission function for thermal radiation of the total atmosphere column, calculated by the radiative scheme of the model. Equation (3) is derived by Mokhov and Petoukhov (1978) using the assumption of radiative equilibrium of an isothermal stratosphere and a linear vertical profile of temperature in the troposphere.

An exponential vertical profile of specific humidity is assumed,

$q(z)=q_{s} \exp \left(\frac{z_{s}-z}{H_{e}}\right)$,

where $H_{e}$ is the water vapor scale height. The air density $\rho$ is described in the Boussinesque approximation as $\rho=\rho_{*} \exp \left(-z H_{0}^{-1}\right)$, where $H_{0}=R T_{*} / g$ is a density scale height of the atmosphere, $R$ is the gas constant for air, $g$ is the acceleration due to gravity.

\subsection{Atmosphere dynamics}

Wind velocity is divided into geostrophic and ageostrophic components:

$\mathbf{u}=\mathbf{u}_{q}+\mathbf{u}_{a}$.

Conventional scale analysis shows that nonstationary nonlinear terms in the atmospheric dynamical equations are negligible for the considered spatial and temporal scales everywhere in the equatorial region, which needs special consideration. Since CLIMBER-2 resolution is low and only a few grid rows correspond to this region, instead of introducing special equations for the equatorial region, we fixed the Coriolis parameter $f(\phi)=f\left( \pm 15^{\circ}\right)$ within the tropical belt $-15^{\circ}<\phi<15^{\circ}$. The geostrophic components of velocity at
Table 1 Atmosphere model parameters

\begin{tabular}{|c|c|c|}
\hline$T_{*}$ & Reference temperature & $273.16 \mathrm{~K}$ \\
\hline$\rho_{*}$ & Reference air density & $1.3 \mathrm{~kg} \mathrm{~m}^{-3}$ \\
\hline$C_{t}$ & Tropopause height parameter & 0.8 \\
\hline$C_{h}$ & Boundary layer parameter & 1.5 \\
\hline$H_{e}$ & Vertical water vapor scale & $2000 \mathrm{~m}$ \\
\hline$C_{\alpha}$ & Ageostrophic velocity parameter & 1 \\
\hline $\begin{array}{l}\Gamma_{0} \\
\Gamma_{1} \\
\Gamma_{2} \\
a_{q}\end{array}$ & Temperature lapse rate parameters & $\begin{array}{l}5.2 \cdot 10^{-3} \mathrm{~K} \mathrm{~m}^{-1} \\
5.5 \cdot 10^{-5} \mathrm{~m}^{-1} \\
10^{-3} \mathrm{~K} \mathrm{~m}^{-1} \\
10^{3}(\mathrm{~kg} / \mathrm{kg})^{-2}\end{array}$ \\
\hline $\begin{array}{l}C_{1} \\
C_{2} \\
C_{3} \\
C_{4} \\
C_{5} \\
C_{6}\end{array}$ & Meridional circulation parameters & $\begin{array}{l}0.006 \mathrm{~m}(\mathrm{~s} \mathrm{~K})^{-1} \\
0.015 \mathrm{~m}(\mathrm{~s} \mathrm{~K})^{-1} \\
0.15 \mathrm{~m}(\mathrm{~s} \mathrm{~K})^{-1} \\
0.10 \mathrm{~m}(\mathrm{~s} \mathrm{~K})^{-1} \\
0.03 \mathrm{~m} \mathrm{(s} \mathrm{K})^{-1} \\
0.006 \mathrm{~m}(\mathrm{~s} \mathrm{~K})^{-1}\end{array}$ \\
\hline $\begin{array}{l}C_{U} \\
C_{T}\end{array}$ & Second moments parameters & $\begin{array}{l}5.0 \\
0.3\end{array}$ \\
\hline $\begin{array}{l}c_{1} \\
c_{2}\end{array}$ & Cloudiness height parameters & $\begin{array}{l}0.2 \\
10^{5} \mathrm{~s}\end{array}$ \\
\hline $\begin{array}{l}a_{1} \\
a_{2} \\
a_{3} \\
a_{4} \\
a_{5}\end{array}$ & Stratus cloudiness parameters & $\begin{array}{l}0.8 \\
0.1 \\
0.3 \\
0.3 \\
10^{-3} \mathrm{~m} \mathrm{~s}^{-1}\end{array}$ \\
\hline $\begin{array}{l}\mathrm{b}_{1} \\
\mathrm{~b}_{2} \\
n_{c m}\end{array}$ & Cumulus cloudiness parameters & $\begin{array}{l}10^{-3} \mathrm{~m} \mathrm{~s}^{-1} \\
30 \cdot 10^{-3} \mathrm{~kg} \mathrm{~kg}^{-1} \\
0.3\end{array}$ \\
\hline $\begin{array}{l}\tau_{0} \\
a_{\tau}\end{array}$ & Water turnover time parameters & $\begin{array}{l}5 \cdot 10^{5} \mathrm{~s} \\
0.5\end{array}$ \\
\hline
\end{tabular}

any height $z$ within the troposphere are obtained using the thermal wind approximation as

$u_{g}(z)=-\frac{1}{a \rho_{*} f} \frac{\partial p_{0}}{\partial \phi}-\int_{0}^{z} \frac{g}{a T_{*} f} \frac{\partial T}{\partial \phi} d z$,
$v_{g}(z)=\frac{1}{a \rho_{*} f} \frac{\partial p_{0}}{\partial \lambda}+\int_{0}^{z} \frac{g}{a T_{*} f} \frac{\partial T}{\partial \lambda} d z$.

where $a$ is the Earth's radius and $p_{0}$ is the sea level pressure.

The components of the surface wind are computed using the Taylor model (see e.g., Hansen et al. 1983) as

$u_{s}=\epsilon\left[u_{g}\left(h_{b}\right) \cos \alpha-v_{g}\left(h_{b}\right) \sin \alpha\right]$,

$v_{s}=\epsilon\left[v_{g}\left(h_{b}\right) \cos \alpha+u_{g}\left(h_{b}\right) \sin \alpha\right]$,

where $u_{g}\left(h_{b}\right), v_{g}\left(h_{b}\right)$ are the components of the geostrophic wind velocity at the top of the PBL. The vertical depth of the PBL is

$h_{b}=C_{h}\left(\frac{2 K}{|f|}\right)^{1 / 2}$

where $K$ is the kinematic vertical viscosity coefficient in the PBL, $\alpha$ is the cross-isobar angle in the SL, and $\epsilon=(1-\sin 2 \alpha)^{1 / 2}$. The cross-isobar angle is determined from the condition that the shear stress be continuous between the Ekman layer and the SL:

$C_{D} U_{s}^{2}=U_{g} \sin \alpha(2|f| K)^{1 / 2}$.

Here $C_{D}$ is the drag coefficient, $U_{s}$ is the surface wind velocity, and $U_{g}=\left[u_{g}\left(h_{b}\right)^{2}+v_{g}\left(h_{b}\right)^{2}\right]^{1 / 2}$. In the approximation of small wind stress at the top of the PBL compared to that at the surface and assuming that $\alpha \ll 1$, the agestrophic wind components averaged over the PBL (denoted by $\langle\ldots\rangle)$ are written as

$\left\langle u_{a}\right\rangle=-\frac{C_{\alpha} \sin \alpha}{a \rho|f|} \frac{\partial p_{0}}{\partial \lambda}$, 
$\left\langle v_{a}\right\rangle=-\frac{C_{\alpha} \sin \alpha}{a \rho|f|} \frac{\partial p_{0}}{\partial \phi}$

The parameter $C_{\alpha}$ can be derived from boundary layer theory and is almost constant. In the free troposphere the ageostrophic components are defined in the form

$u_{a}=F_{u}(z)\left\langle u_{a}\right\rangle . \quad v_{a}=F_{v}(z)\left\langle v_{a}\right\rangle$,

where $F_{u}(z), F_{v}(z)$ are obtained analogous to the Taylor model in the PBL, but with a vertical viscosity coefficient corresponding to synoptic and mesoscale eddies in the free troposphere. The stratosphere is represented by one isothermal layer, and it is necessary to find only the vertically averaged velocity in the stratosphere which has to satisfy the condition of zero vertical mass flux at the upper boundary of the atmosphere $H_{a}$. This condition is automatically fulfilled if we demand that

$\int_{z_{s}}^{H_{a}} \rho u^{*} d z=\int_{z_{s}}^{H_{a}} \rho v^{*} d z=0$.

Hereafter an asterix denotes the deviation from the zonally averaged value for any variable $x$ :

$x^{*}=x-\bar{x}$, where $\bar{x}=\frac{1}{2 \pi} \int_{0}^{2 \pi} x d \lambda$.

To close the system of dynamical equations it is necessary to find the sea level pressure. For this we use a decomposition of sea level pressure

$p_{0}=\overline{p_{0}}+p_{0}^{*}$.

The azonal component of pressure is described in the model by using the interrelation between long-term large-scale azonal temperature and pressure fields in quasi-stationary planetary-scale waves (Blinova 1958)

$p_{0}^{*}=-\frac{g \overline{p_{0}} \overline{H_{t}}}{2 R{\overline{T_{0}}}^{2}} T_{0}^{*}$.

where $T_{0}$ is a "sea level temperature" defined as $T_{0}=T_{a}+z_{S} \Gamma$. We neglect the phase shift between temperature and pressure fields because this shift is below the spatial resolution of CLIMBER-2.

To find the zonally averaged sea level pressure we employ a special parametrization for the zonally averaged component of meridional velocity (see also Fig. 3). The basic assumption is that the present-day structure of the zonally averaged circulation with three pairs of cells (Hadley, Ferrel and polar) is robust and will exist under different climatic conditions. It is assumed that the average latitudinal width of every cell is approximately $\pi / 6$ and that variations of the position of the borders between the cells $\phi_{i}$ follow the variations of the thermal equator, with amplitude decreasing toward the poles. The zonally averaged meridional wind in the atmosphere is represented in the form

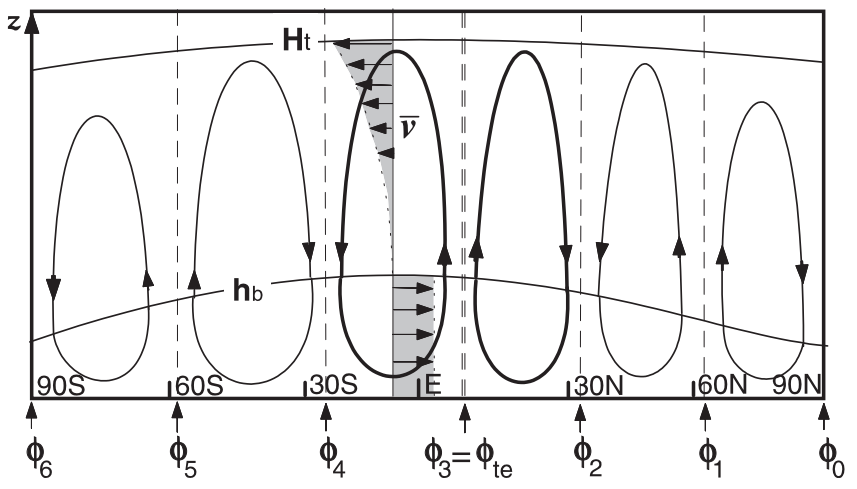

Fig. 3 Vertical structure of the zonally averaged atmospheric circulation in the model $\bar{v}(\phi, z)=v_{1}(\phi) v_{2}(z)$.

The first term in Eq. (18) is the zonally averaged meridional velocity in the PBL which is computed as

$v_{1}(\phi)=(-1)^{i} C_{i}\left(\frac{\tilde{T}_{i}}{T_{*}}\right)^{3}\left|\Delta \tilde{T}_{i}\right| \sin \left(\pi \frac{\phi-\phi_{i}}{\phi_{i-1}-\phi_{i}}\right)$,

$$
\phi_{i}<\phi \leq \phi_{i-1}, \quad i=1,6 .
$$

where

$$
\begin{aligned}
\phi_{i}= & \frac{(3-i) \pi}{6}+\frac{\phi_{t e}}{(|3-i|+1)^{2}} \\
& \text { for } i=1,5 \text { and } \phi_{0}=\pi / 2, \quad \phi_{6}=-\pi / 2 .
\end{aligned}
$$

$C_{i}$ are empirical constants prescribed for every cell. The average temperature for the $i$-th cell is defined as

$\tilde{T}_{i}=\left(\sin \phi_{i-1}-\sin \phi_{i}\right)^{-1} \int_{\phi_{i-1}}^{\phi_{i}} \overline{T_{0}} \cos \phi d \phi$,

and $\Delta \tilde{T}_{i}=\bar{T}_{0}\left(\phi_{i}\right)-\bar{T}_{0}\left(\phi_{i-1}\right)$ represents the meridional temperature gradient within the $i$-th cell. The position of the thermal equator is defined as

$\phi_{t e}=2 \frac{\tilde{T}_{3}-\tilde{T}_{4}}{\tilde{T}_{3}+\tilde{T}_{4}-\tilde{T}_{2}-\tilde{T}_{5}}$

Equation (19) represents the description of the mean meridional circulation in terms of linked heat engines of the first and second genus (see e.g., Sommerfeld 1952; Lorenz 1955) as described in Petoukhov (1976). This approach can be considered as a spatially aggregated version of the traditional description of meridional atmospheric circulation based on the solution of 2-D differential equations for the zonally averaged atmospheric velocity (e.g., Saltzman and Vernekar 1972; Schneider and Lindzen 1977; Held and Hou 1980; Lindzen and Hou 1988). In particular, this approach implicitly accounts for the meridional synoptic angular momentum flux $\left(u^{\prime} v^{\prime}\right)$, since the latter, as a first approximation, can be expressed in terms of the meridional temperature gradient (Williams and Davis 1965).

The vertical structure of the zonally averaged meridional wind is prescribed in the form

$v_{2}(z)=\left\{\begin{array}{lll}1 & \text { if } & 0<z<h_{b} \\ C_{v}\left(z-h_{b}\right)^{2} & \text { if } \quad h_{b} \leq z \leq H_{t} \\ 0 & \text { if } \quad H_{t}<z \leq H_{a}\end{array}\right.$

where the value of $C_{v}$ is obtained from the condition $\int_{0}^{H_{t}} v_{2} \rho d z=0$.

The zonally averaged sea level pressure is computed, using Eq. (13) and neglecting the influence of zonally averaged orography, as

$\frac{\partial \overline{p_{0}}}{\partial \phi}=-\frac{v_{1}(\phi) a f \rho_{*}}{C_{\alpha} \overline{\sin \alpha}}$.

\subsection{Energy and water balance equations}

To reduce the minimal time step of the model, which is constrained by the wind velocity, it is useful to decompose the vector of wind velocity into a thermal wind $\mathbf{u}_{t}$ (second terms in the right hand side of Eqs. (6), (7)) and a "nonthermal" component $\mathbf{u}_{n}$ :

$\mathbf{u}=\mathbf{u}_{t}+\mathbf{u}_{n}$.

Taking into account that thermal wind contributes to the advection of temperature only through the beta-effect, the horizontal components of thermal wind can be excluded from the temperature equation, which allows us to use a time step of integration up to one day. The energy balance equation, vertically integrated from the surface to the top of the atmosphere, is written in flux form as 


$$
\begin{aligned}
\frac{\partial Q_{T}}{\partial t}= & -\frac{1}{a \cos \phi}\left[\frac{\partial}{\partial \lambda} \int_{z_{s}}^{H_{a}} \rho\left(u_{n} \theta+\widehat{u^{\prime} \theta^{\prime}}+M_{\lambda}^{\theta}\right) d z\right. \\
& \left.+\frac{\partial}{\partial \phi} \int_{z_{s}}^{H_{a}} \cos \phi \rho\left(v_{n} \theta+\widehat{v^{\prime} \theta^{\prime}}+M_{\phi}^{\theta}\right) d z\right]-\int_{z_{s}}^{H_{a}} \rho w_{t}\left(\Gamma_{a}-\Gamma\right) d z \\
& +c_{v}^{-1}\left(S_{a}+R_{s}-R_{t}+L_{e} P_{w}+L_{s} P_{s}+F_{h}\right),
\end{aligned}
$$

where $Q_{T}=\int_{z_{s}}^{H_{a}} \rho T d z$ is the heat content of atmosphere column, $\theta=T_{a}+\Gamma_{a}\left(z-z_{s}\right)$ is the potential temperature, $c_{v}$ is the specific heat of air at constant volume, and $w_{t}$ is the vertical component of velocity due to thermal wind computed in the troposphere

$w_{t}(z)=\frac{1}{\rho} \int_{z_{s}}^{z} \rho v_{t}(z) \frac{\partial f}{f \partial \phi} d z$.

In the stratosphere $w_{t}$ is assumed to linearly decrease with pressure.

The equations for synoptic ensemble characteristics $\widehat{\left(u^{\prime} u^{\prime}\right.}, \widehat{u^{\prime} T^{\prime}}, \widehat{u^{\prime} q^{\prime}}$, etc.) are obtained in the model applying the conventional method of deriving a set of equations for synoptic-scale components similar to Saltzman and Vernekar (1972). Stone and Yao (1990), and Held and Larichev (1996). The assumption that synoptic components are a Gaussian process in space and time (Hasselmann 1976; Lemke 1977) allows us to reduce an infinite set of equations to a set of equations for the second moments only. To derive model equations for the second moments of synoptic-scale components we use further simplifications (Petoukhov and Ganopolski 1994). Namely, the equations are rewritten for the $\beta$-plane, synoptic components of motion are assumed nondivergent and quasi-geostrophic (Burger 1958), with Rossby horizontal and vertical spatial scales. We also use the assumption of a linear vertical profile of temperature in the troposphere.

Horizontal heat transport due to synoptic-scale and mesoscale processes is described in the troposphere as macroturbulent diffusion

$\widehat{u^{\prime} \theta^{\prime}}=\widehat{u^{\prime} T^{\prime}}=-A_{h} \frac{\partial T}{a \cos \phi \partial \lambda}, \quad \widehat{v^{\prime} \theta^{\prime}}=\widehat{v^{\prime} T^{\prime}}=-A_{h} \frac{\partial T}{a \partial \phi}$,

with an isotropic coefficient of horizontal diffusion $A_{h}$ expressed through the second moment of the synoptic velocity

$A_{h}=C_{T} \frac{\left.\widehat{\left(u^{\prime 2}\right.}+\widehat{v^{\prime 2}}\right)^{1 / 2} L_{O}}{\alpha_{0}}$,

where

$\widehat{u^{\prime 2}}=\widehat{v^{\prime 2}}=C^{*} \alpha_{0}^{-2}\left|\nabla T_{0}\right|^{2} Z^{2}\left(0.5-\frac{\Gamma_{1} Z}{3}\right)$,

and

$C^{*}=C_{U} \frac{g^{2} L_{O} \beta_{0}}{f_{0}^{3} T_{*}^{2}}, \quad f_{0}=f(\pi / 4), \quad \beta_{0}=\left.\frac{\partial f}{a \partial \phi}\right|_{\phi=\pi / 4}$,

$Z=\max \left(z, h_{b}\right), L_{O}=\left(R T_{0}\right)^{1 / 2} /\left(4 f_{0}\right)$ is the Obukhov length scale, $\alpha_{0}=\left((R / g)\left(\Gamma_{a}-\Gamma\right)\right)^{1 / 2}$ is the parameter of static stability, and $\Gamma_{a}$ is the adiabatic lapse rate. In the stratosphere we neglect macroturbulent diffusion. $M_{\lambda}^{\theta}$ and $M_{\phi}^{\theta}$ stand for mesoscale horizontal diffusion. $S_{a}$ is the solar radiation absorbed in the atmosphere, $R_{s}$ and $R_{t}$ are the terrestrial radiation fluxes at the Earth's surface and at the top of the atmosphere, and $F_{h}$ is the sensible heat flux at the surface. The terms $P_{w}$ and $P_{s}$ denote precipitation in the liquid and snow forms, while $L_{e}$ and $L_{s}$ designate the corresponding latent heats. Latent and sensible heat fluxes are computed using bulkformulae as the functions of near-surface wind speed, which is computed as

$U_{s}=\left(u_{s}^{2}+v_{s}^{2}+\widehat{u_{s}^{\prime 2}}+\widehat{v_{s}^{\prime 2}}\right)^{1 / 2}$.

The synoptic components of surface wind speed are computed from their values at the top of the PBL

$\widehat{u_{s}^{\prime 2}}=\widehat{u^{\prime 2}}\left(h_{b}\right)(\epsilon \cos \alpha)^{2}, \quad \widehat{v_{s}^{\prime 2}}=\widehat{v^{\prime 2}}\left(h_{b}\right)(\epsilon \cos \alpha)^{2}$.

The water vapor balance equation integrated from the underlying surface to the upper boundary of the atmosphere reads

$$
\begin{aligned}
\frac{\partial Q_{q}}{\partial t}=-\frac{1}{a \cos \phi} & {\left[\frac{\partial}{\partial \lambda} \int_{z_{s}}^{H_{a}} \rho\left(u q+\widehat{u^{\prime} q^{\prime}}+M_{\lambda}^{q}\right) d z\right.} \\
& \left.+\frac{\partial}{\partial \phi} \int_{z_{s}}^{H_{a}} \cos \phi \rho\left(v q+\widehat{v^{\prime} q^{\prime}}+M_{\phi}^{q}\right) d z\right] \\
& +E-P,
\end{aligned}
$$

where $Q_{q}=\int_{z}^{H_{a}} \rho q d z$ is the water content in the atmosphere column. The terms $E$ and $P$ in Eq. (32) stand for evaporation/ evapotranspiration and total precipitation respectively, while $\widehat{u^{\prime} q^{\prime}}$ and $v^{\prime} q^{\prime}$ describe water vapor fluxes due to the synoptic-scale components computed as

$\widehat{u^{\prime} q^{\prime}}=-A_{h} \frac{\partial q}{a \cos \phi \partial \lambda}, \quad \widehat{v^{\prime} q^{\prime}}=-A_{h} \frac{\partial q}{a \partial \phi}$.

$M_{\lambda}^{q}$ and $M_{\phi}^{q}$ represent horizontal components of mesoscale diffusion of water vapor. In Eq. (32), in contrast to Eq. (25), we use the total wind velocity, but due to the fact that the major part of atmospheric water vapor is contained in the lower troposphere, the high values of thermal wind in the upper troposphere do not affect the stability of the numerical integration of Eq. (32).

\subsection{Atmosphere diabatics}

\section{Radiation}

To compute the longwave radiation (LWR) fluxes, the atmosphere column is subdivided into 16 levels, and the temperature and humidity for each level are computed using Eqs. (1) and (4). The longwave radiative scheme accounts for water vapor, carbon dioxide and ozone. LWR fluxes are calculated using the integral transmission functions (ITF) of the radiatively active constituents mentioned. The ITFs for water vapor, carbon dioxide and ozone are computed following Mokhov and Petoukhov (1978) and Gorchakova ad Leont'eva (1991). Clouds are treated as black-body radiators. Total LWR fluxes in each grid cell are taken as weighted sums of the clear sky flux and flux in the presence of an effective cloud layer.

The total shortwave radiation range is divided into two subintervals: ultraviolet + visible and near infrared. The radiative scheme accounts for water vapor, clouds, aerosols and ozone. The cloud albedo is a function of solar zenith angle and the optical thickness of the clouds (Feigelson et al. 1975). The aerosol optical properties are treated following the Yamamoto and Tanaka (1972) scheme. The ITF of ozone is taken from Lacis and Hansen (1974). In the near infrared band the absorption due to water vapor is described according to Feigelson et al. (1975).

\section{Cloudiness and precipitation}

Two types of clouds are considered in the model: large-scale stratiform and cumuli. The first type is represented by a one-layer effective cloudiness. The height of this layer $z_{c}$ is determined as

$z_{c}=h_{b}+c_{1} H_{t}+c_{2} w\left(z_{c}\right)$.

The stratus cover is assumed to be dependent on relative humidity $r=q_{s} / q_{\text {sat }}\left(T_{a}\right)$, where $q_{\text {sat }}\left(T_{a}\right)$ is the equilibrium specific humidity of the temperature $T_{a}$; and effective vertical velocity $w_{e}$ (Dushkin et al. 1960):

$n_{s}=r^{1.5}\left(a_{1}+a_{2} F_{c}\left(w_{e}\right)\right)$,

where

$w_{e}=w\left(z_{c}\right)+a_{3} w_{s}+a_{4} w_{o}$.

Here $w\left(z_{c}\right)$ is the large-scale vertical velocity at cloudiness height $z_{c}, w_{s}$ is the synoptic vertical velocity, which is defined similar to the synoptic components of horizontal velocity (Eq. 29). The orographic component of vertical velocity $w_{o}$ is proportional to the near-surface wind and standard deviation of the surface orography, and

$F_{c}\left(w_{e}\right)=0.5\left(1+\tanh \left(\frac{w_{e}}{a_{5}}\right)\right)$. 
The fraction of cumulus cloudiness $n_{c}$ is described as a function of effective vertical velocity and surface specific humidity:

$n_{c}=n_{c m} \tanh \left(\frac{w_{e}}{b_{1}}\right) \tanh \left(\frac{q_{s}}{b_{2}}\right)$ if $w_{e}>0, \quad$ and $\quad n_{c}=0$ if $w_{e}<0$.

Finally, the total cloudiness fraction $n$ is obtained as

$n=1-\left(1-n_{c}\right)\left(1-n_{s}\right)$.

Following Petoukhov (1982) the precipitation is computed as

$P=\frac{Q_{q} n}{\tau}$,

where

$\tau=\tau_{0}\left(1-a_{\tau} F_{c}\left(w_{e}\right)\right)$,

is the turnover time of water in the atmosphere. Due to the strong dependence of precipitation on relative humidity, normally specific

Table 2 The Earth's radiation and energy balance, expressed as a percentage of net incoming solar radiation $\left(342 \mathrm{Wm}^{-2}\right)$

\begin{tabular}{lcc}
\hline & Model & $\begin{array}{l}\text { Kiehl and } \\
\text { Trenberth (1996) }\end{array}$ \\
\hline Incoming solar radiation & 100 & 100 \\
Reflected solar radiation & 30.6 & 31.2 \\
Outgoing longwave radiation & 69.5 & 68.8 \\
Absorbed by atmosphere & 19.5 & 19.5 \\
Absorbed by surface & 50.0 & 49.1 \\
Back radiation & 96.1 & 94.7 \\
Terrestrial radiation & 115.4 & 114.0 \\
Sensible heat surface flux & 7.1 & 7.0 \\
Evapotranspiration & 24.4 & 22.8 \\
\hline
\end{tabular}
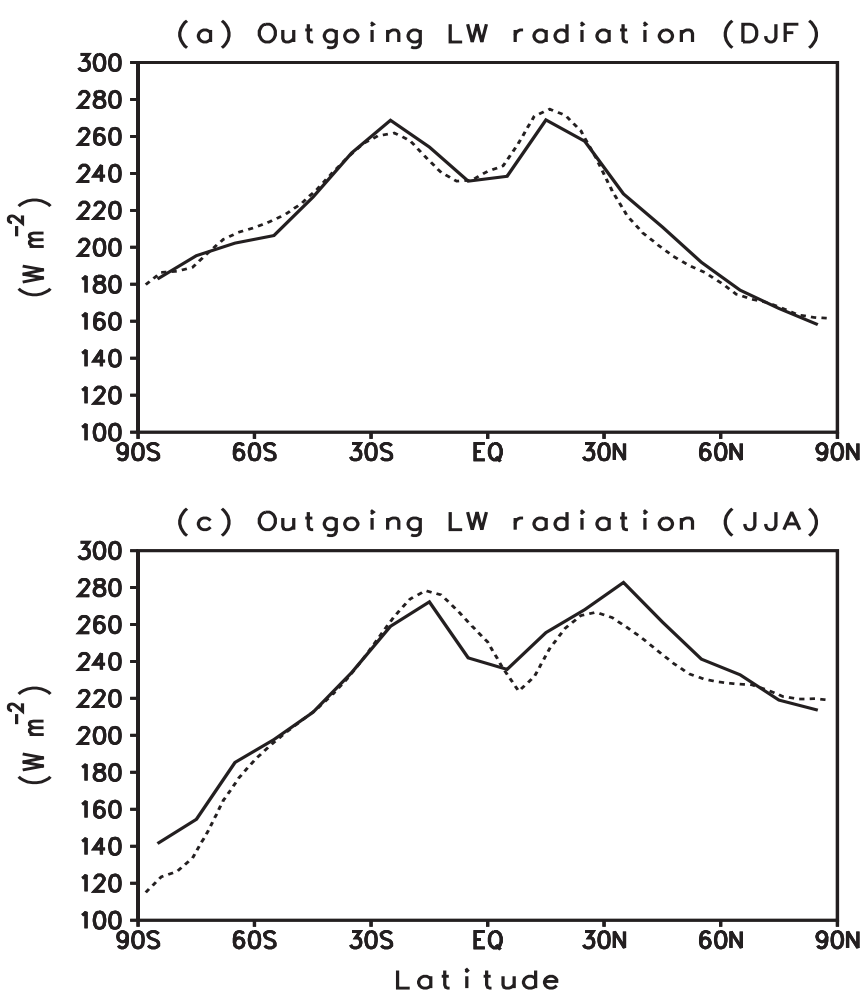

humidity of the air does not reach saturation. To exclude the relatively rare case when the atmosphere becomes oversaturated, the relative humidity is controlled on each time step. If relative humidity exceeds 0.95 , the water content above this threshold is removed from the atmospheric column and is added to the precipitation. The fraction of precipitation in the form of snow is assumed to be equal to unity if $T_{a}<-5^{\circ} \mathrm{C}$, and equal to zero if $T_{a}>5^{\circ} \mathrm{C}$. In between these values, a linear dependence on temperature is prescribed.

\section{Atmosphere-surface interface}

The atmosphere-surface interface (ASI) is the module which (1) provides the linkage between other modules

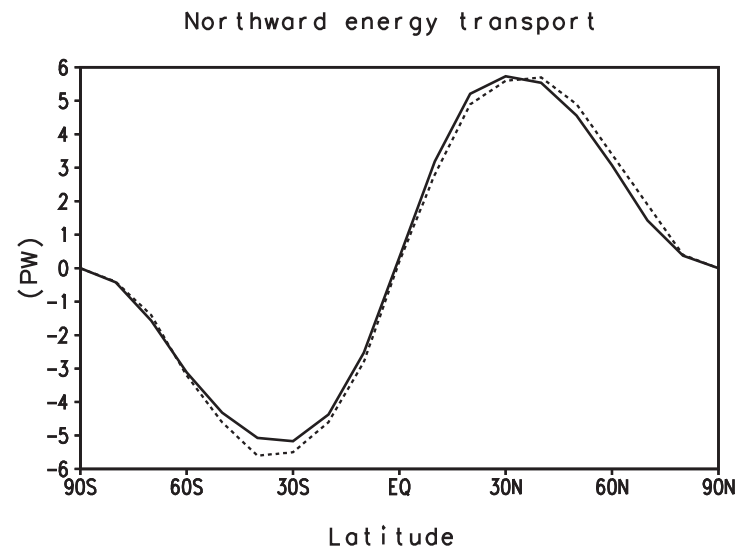

Fig. 5 Annual meridional energy transport in the atmosphere-ocean system. Model, solid line, observed data, dashed

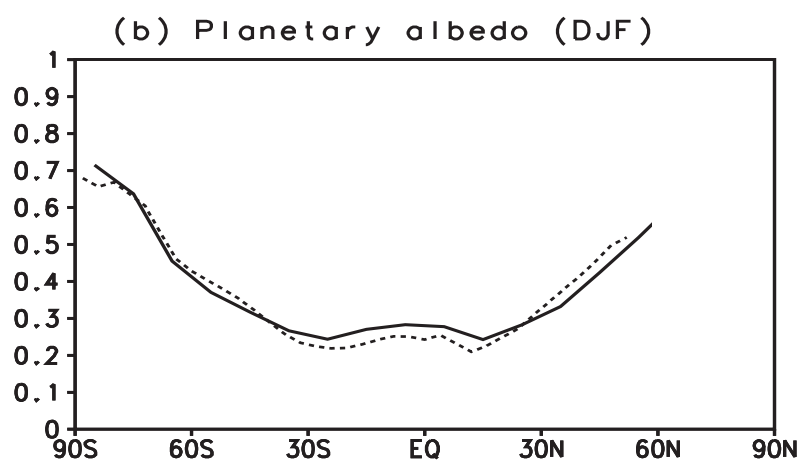

(d) PIanetary albedo (JJA)

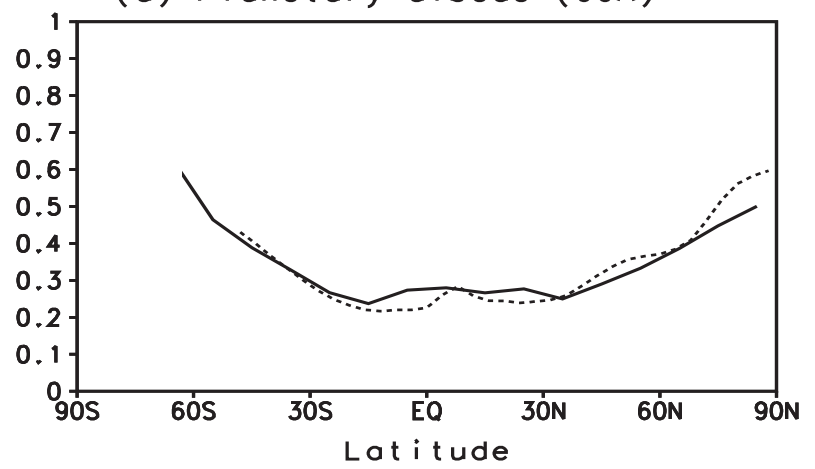

Fig. 4a-d a, c Zonally averaged outgoing longwave radiation at the top-of-the-atmosphere and $\mathbf{b}, \mathbf{d}$ planetary albedo for $\mathbf{a}, \mathbf{b}$ northern winter, and $\mathbf{c}, \mathbf{d}$ summer seasons. Model, solid line, observed data, dashed 
(a) SLP (DJF)

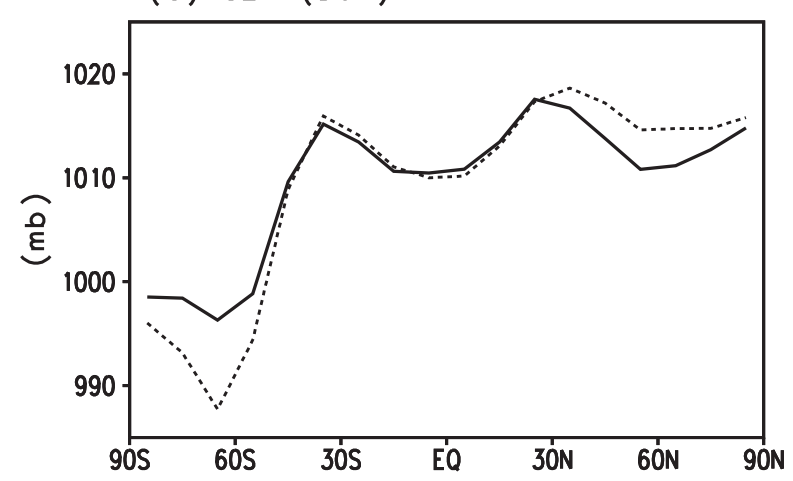

(b) SLP (JJA)

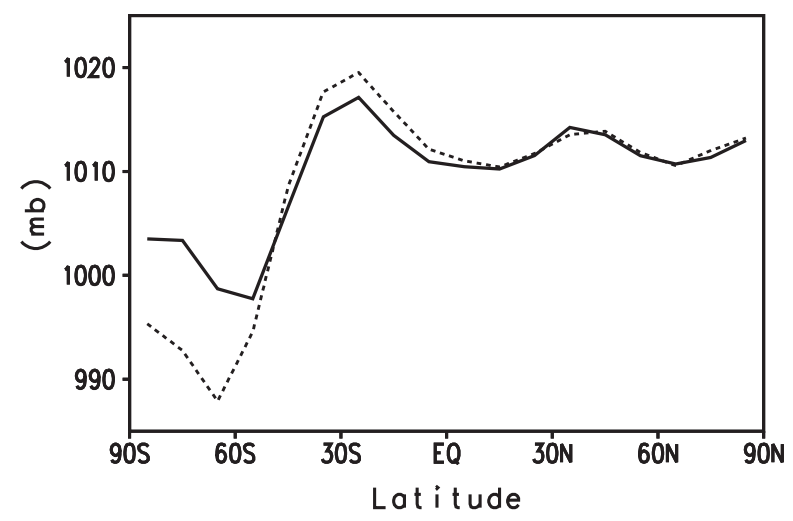

Fig. 6a, b Zonally averaged sea level pressure for a northern winter and $\mathbf{b}$ summer. Model, solid line, observed data, dashed through the fluxes of energy and substances; and (2) describes the land surface processes. ASI is based on the Biosphere-Atmosphere Transfer Scheme (BATS) by Dickinson et al. (1986), and was simplified and modified for the level of spatial and temporal aggregation and degree of complexity of CLIMBER-2.

The ASI distinguishes six surface types: open water surface, sea ice, forest, grassland, desert and glaciers. Different types can coexist in one grid cell. For each type, state variables (temperature, soil moisture, etc.) as well as surface fluxes are calculated separately. In doing so we assume that the characteristics of the free atmosphere are horizontally homogeneous within each grid cell. The distribution of the ice-free land between forest, grass and desert can be either prescribed based on empirical data or computed by the terrestrial vegetation module. The latter is a dynamical global vegetation model based on continuous bioclimatic classification (see Brovkin et al. 1997). In equilibrium with the climate, a fraction of each plant functional type (trees and grasses) is a continuous function of the climate only. The changes in vegetation cover directly affect the climate system through albedo, roughness length, and transpiration. The fraction of the land covered by snow is a function of snow thickness and air temperature.

Surface albedo is calculated (or prescribed) for every surface type for clear sky and cloudy conditions in the visible and near infrared bands. The albedo for snowfree vegetation (both forest and grass) is estimated as a function of leaf area index, which is computed in the (a) SLP, model (DJF)

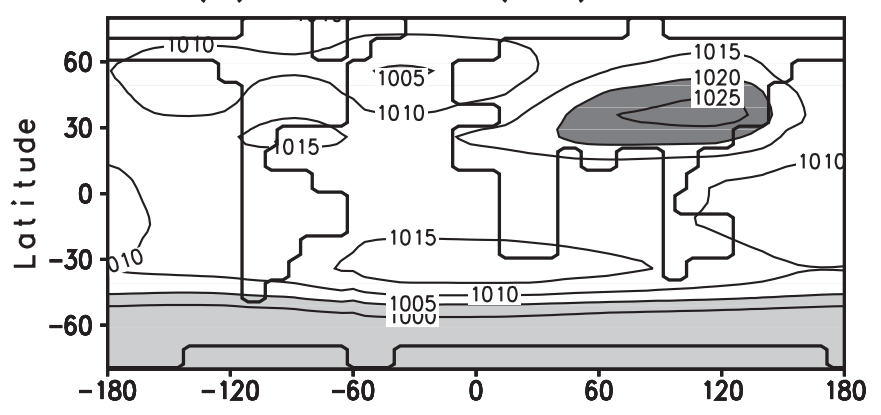

(c) SLP, model (JJA)

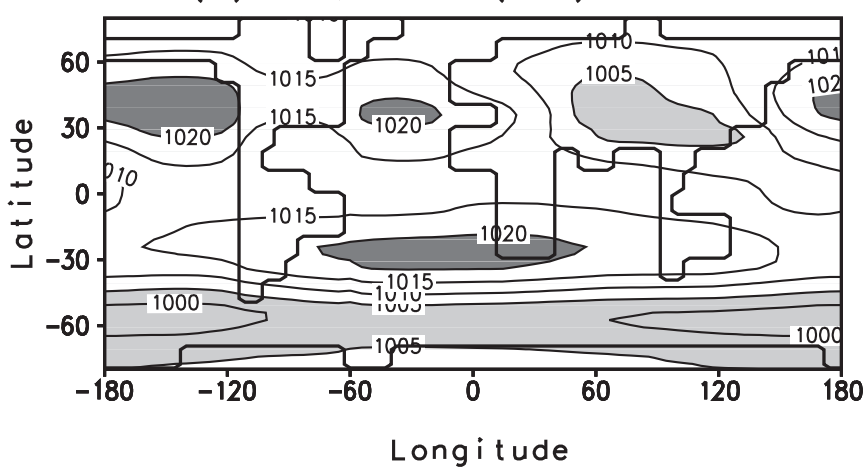

(b) SLP, observ (DJF)

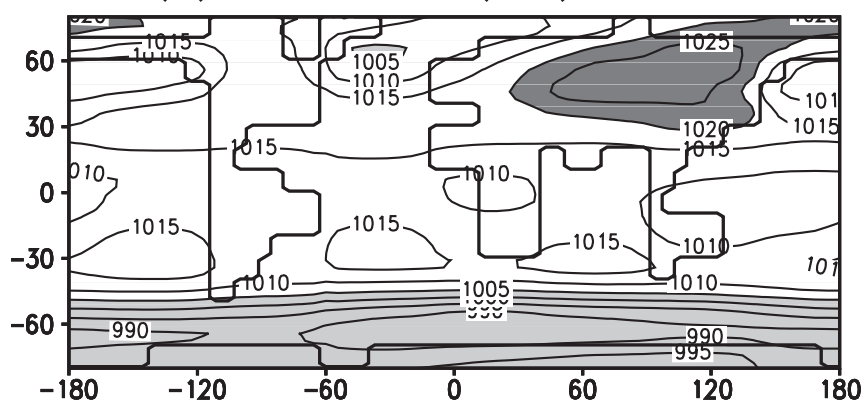

(d) SLP, observ (JJA)

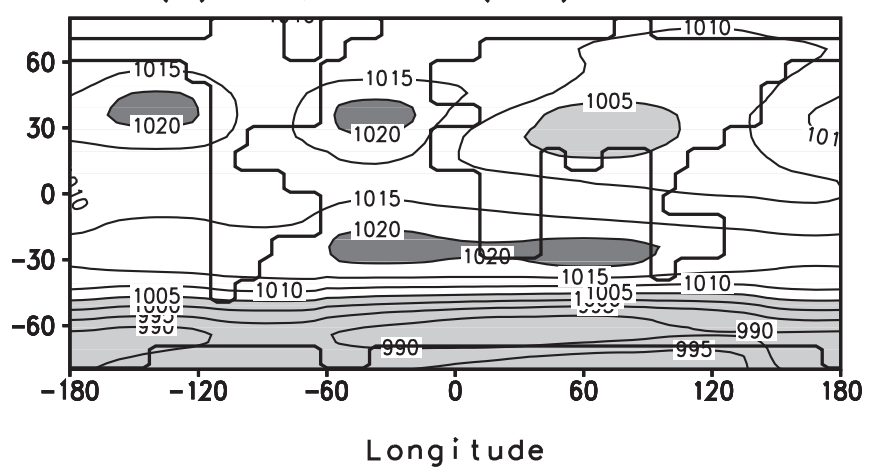

Fig. 7a-d Geographical distribution of sea level pressure in mb. a Model winter; $\mathbf{b}$ observed winter; $\mathbf{c}$ model summer; $\mathbf{d}$ observed summer 
terrestrial vegetation model. The albedo of bare soil is prescribed for every grid cell. For land partly covered by snow, the albedo for every surface type is computed as a weighted sum of snow free and snow covered albedo. The fraction of vegetation covered by snow depends on snow thickness and type of vegetation following Dickinson et al. (1986).

ASI employs a two-layer soil model. The water balance in the upper soil layer is determined by the sum of precipitation, evaporation and transpiration, melting of snow, runoff and drainage. Surface runoff depends on relative soil moisture of the upper soil layer and precipitation. Drainage is assumed to be only downward and depends on relative soil moisture. Transpiration is computed similar to BATS. Annual runoff from every land grid cell is allocated to one or several corresponding oceanic grid cells and is added to the surface fresh water flux to the ocean. The matrix of allocation coefficients is defined to account for the catchment areas of the individual ocean basins.

\section{Ocean module}

The ocean module describes ocean dynamics/thermodynamics, sea ice and ocean carbon cycle and is based
Fig. 9 a, c Surface wind and b, $\mathbf{d}$ easterly wind stress, in $\mathbf{a}, \mathbf{b}$ northern winter and $\mathbf{c}, \mathbf{d}$ summer, zonally averaged over the ocean. Model, solid line, observed data, dashed

on the multibasin zonally averaged model of Stocker et al. (1992). It has 11 uneven vertical levels with an upper mixed layer of $50 \mathrm{~m}$ thickness. The module simulates the zonally averaged temperature, salinity, meridional and vertical velocities for three individual ocean basins (Atlantic, Pacific and Indian) for latitudes where they are separated by continents, and their extensions (meridional sectors) towards the poles in the Arctic and Southern Oceans. For the latitudinal belts without any meridional boundaries (circumpolar oceans), the module also calculates the zonally averaged zonal component of velocity based on the meridional density gradients and assuming zero pressure gradient at the bottom. The coefficients of horizontal and vertical diffusion vary in space following Bryan and Lewis (1979).

The sea ice module is based on the one-layer thermodynamic Semtner (1976) model with simple treatment of advection and diffusion. It calculates the sea-ice fraction and thickness based on the sea-ice mass balance and a relation between ice thickness and fraction. The (a) Zonal wind (DJF)

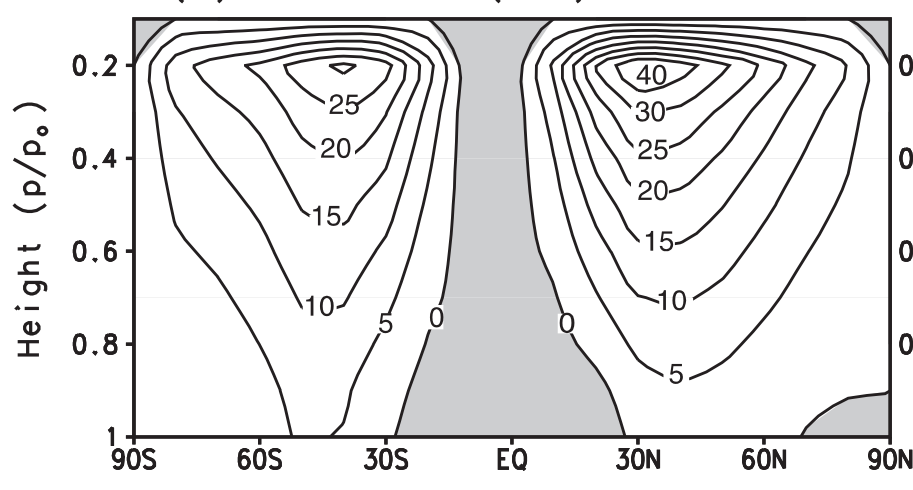

(b) Zonal wind (JJA)

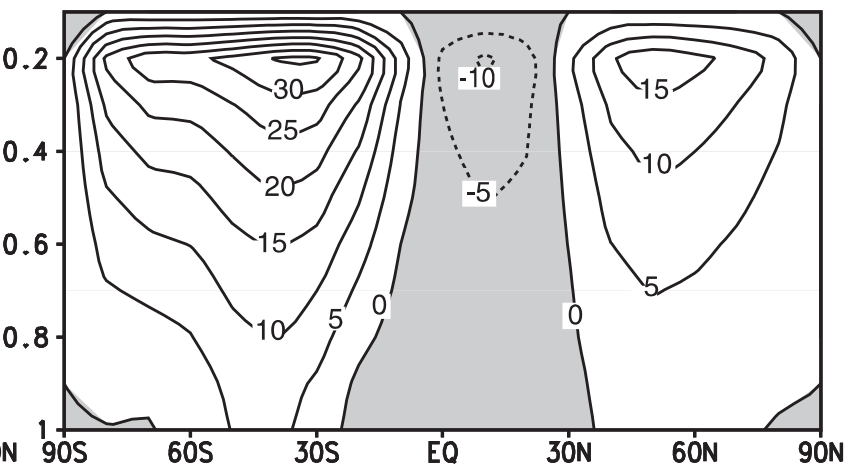

(c) Merid mass transport (DJF)

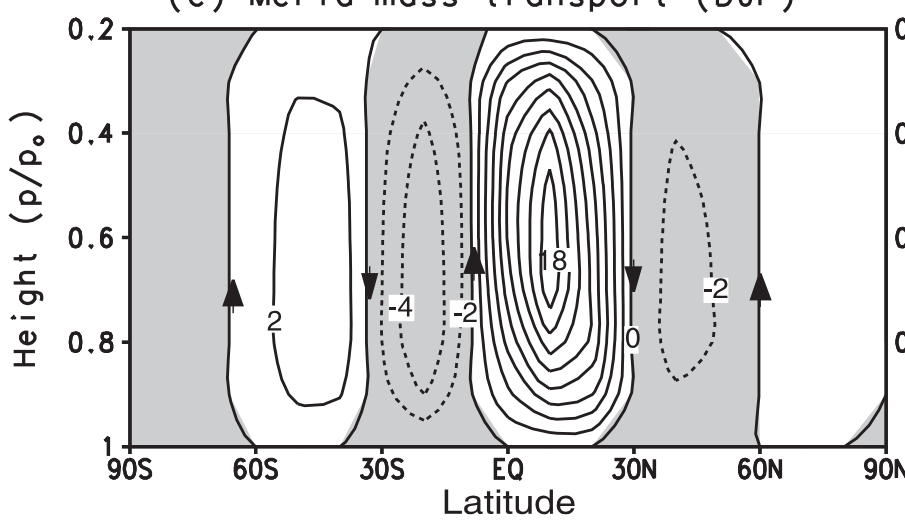

(d) Merid mass transport (JJA)

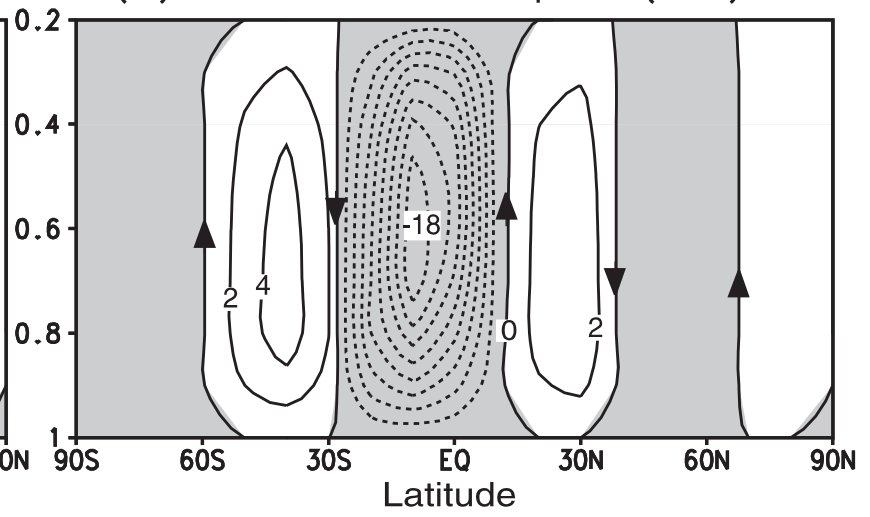

Fig. 8a-d Modeled zonally averaged circulation in the atmosphere. a Zonal wind, northern winter $\mathbf{b}$ northern summer. Units are $\mathrm{m} \mathrm{s}^{-1}$. c Meridional mass transport, winter d summer. Units are $10^{10} \mathrm{~kg} \mathrm{~s}^{-\mathrm{i}}$

Fig. 10a-d Zonally averaged surface air temperature over a, $\mathbf{c}$ land and $\mathbf{b}, \mathbf{d}$ oceans in $\mathbf{a}, \mathbf{b}$ northern winter and $\mathbf{c}, \mathbf{d}$ summer 

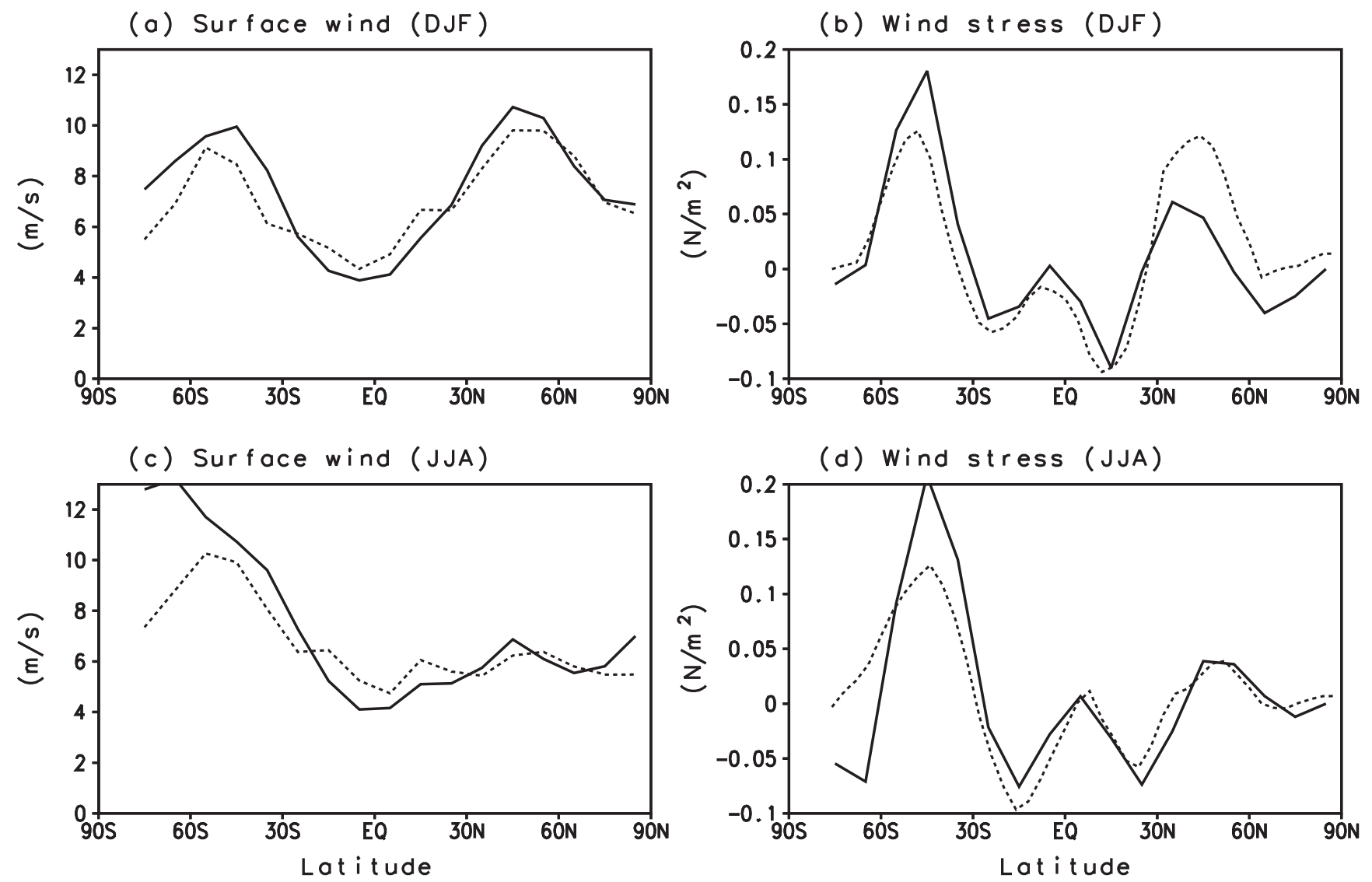

(a) Air temp, I and (DJF)

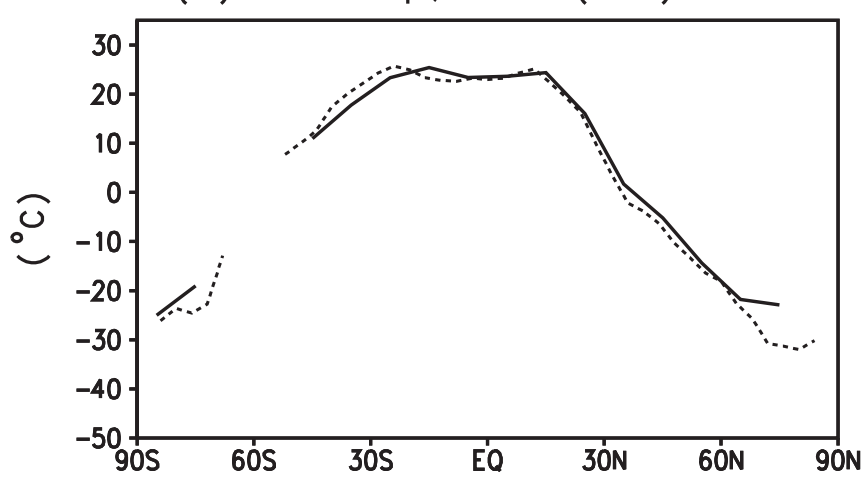

(b) Air temp, ocean (DJF)

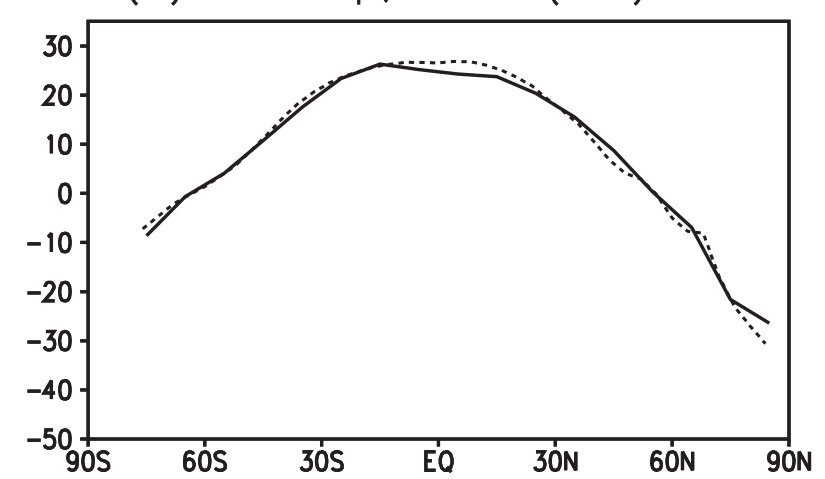

(c) Air temp, land (JJA)

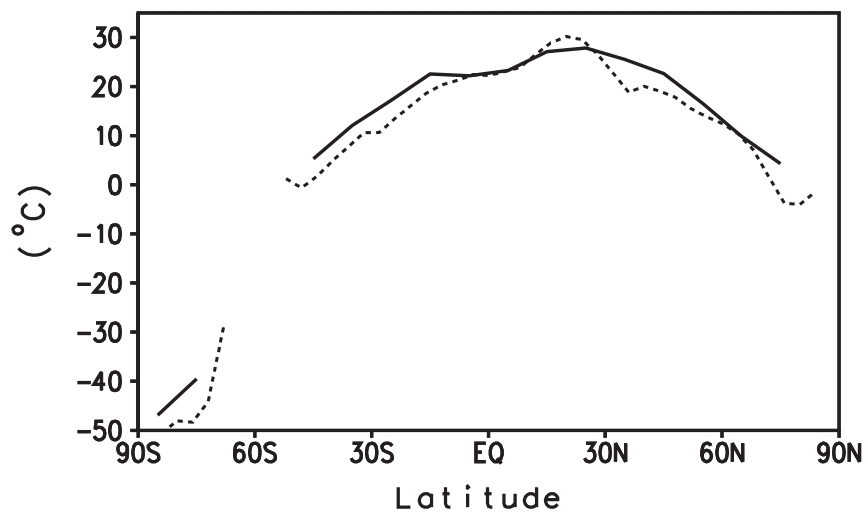

(d) Air temp, ocean (JJA)

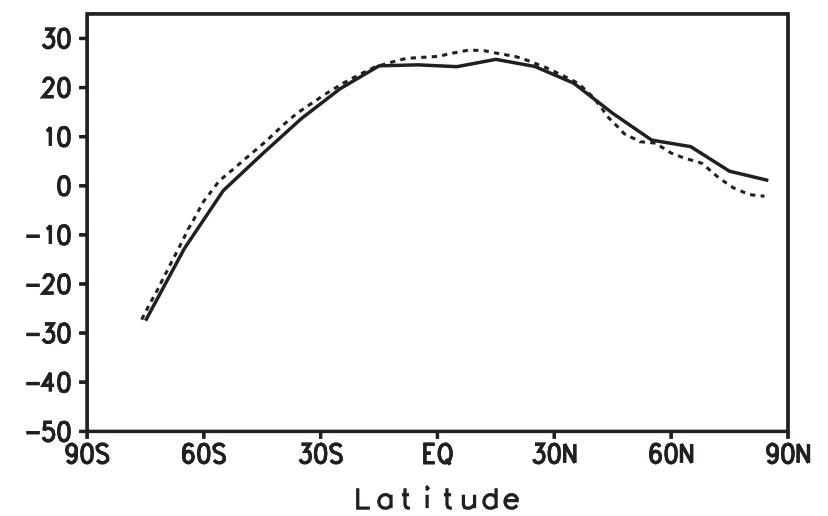


(a) Air temperature model - obs (DJF)

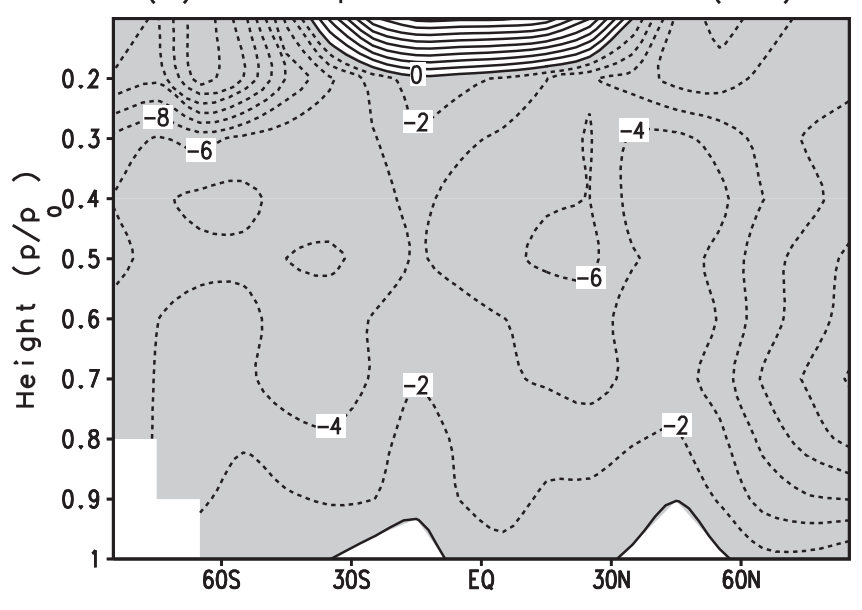

(b) Air temperature model - obs (JJA)

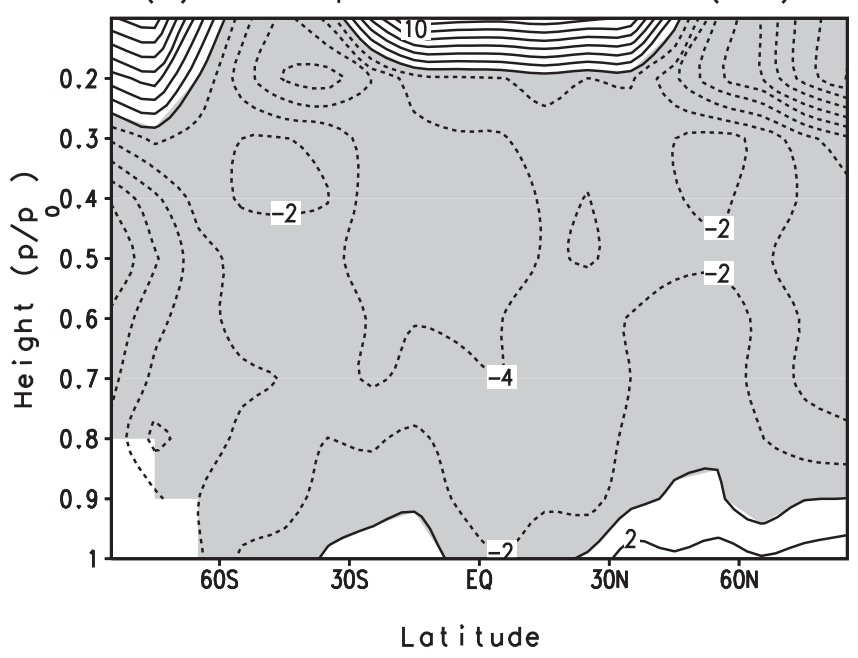

Fig. 11a, b Difference between zonally averaged modeled and observed atmosphere temperature in a northern winter and $\mathbf{b}$ summer. Contour $2 \mathrm{~K}$, negative values shaded

effective coefficient of heat diffusion in the sea ice depends on the thickness of snow cover. Surface sea-ice temperature is calculated in ASI. Due to the low spatial resolution an attempt is made to account for spatial inhomogeneity within one grid cell. To this end it is assumed that sea ice can appear within a grid cell when its SST drops below $0^{\circ} \mathrm{C}$. In the interval between $0^{\circ} \mathrm{C}$ and the sea water freezing point of $-1.8^{\circ} \mathrm{C}$, the sea-ice fraction increases linearly with the decrease of SST. After SST reaches freezing point, the fraction of open water is assumed to be inversely proportional to sea-ice thickness. The ice is freely transported (no ice rheology) by advection and horizontal diffusion. To account for the specific conditions near Antarctica in the Weddel and Ross seas, where Antarctic bottom water is formed, a small northward velocity $(0.05 \mathrm{~m} / \mathrm{s})$ is added to the ice velocity in the grid cells in Atlantic and Pacific in the latitudinal belt $70-80 \mathrm{~S}$.
Fig. 12a-d The same as Fig. 10 but for precipitation

\section{Model tuning and coupling}

Careful tuning is essential for a new model, as some parameter values are not known a priori and incorrect choices of parameter values compromise the quality and reliability of simulations. At the same time tuning can be abused (getting the right results for the wrong reasons) if there are too many free parameters. To avoid this we adhered to a set of common-sense rules for good tuning practice:

1. Parameters which are known empirically or from theory must not be used for tuning.

2. Whereever possible parametrizations should be tuned separately against observed data, not in the context of the whole model. (Most of the parameters values in Table 1 were obtained in this way and only few of them were determined by tuning the model to the observed climate).

3. Parameters must relate to physical processes, not to specific geographic regions (hidden flux adjustments).

4. The number of tuning parameters must be much smaller than the degrees of freedom predicted by the model. (In our case the predicted degrees of freedom exceed the number of tuning parameters by several orders of magnitude).

To apply the coupled climate model for simulations of climates substantially different from the present, it is crucial to avoid any type of flux adjustment. One of the reasons for the need of flux adjustments in many general circulation models is their high computational cost, which makes optimal tuning difficult. The high speed of CLIMBER-2 allows us to perform many sensitivity experiments required to identify the physical reasons for model problems and the best parameter choices. A physically correct choice of model parameters is fundamentally different from a flux adjustment; only in the former case the surface fluxes are part of the proper feedbacks when the climate changes.

To prevent a climate drift (gradual evolution of the atmosphere and the ocean from their states obtained separately driven by realistic boundary conditions towards a new equilibria of fully coupled system) it is necessary to have close agreement between the surface fluxes of energy and water diagnosed in the atmosphere and the ocean modules prior to coupling (e.g. Gleckler et al. 1995). Since CLIMBER-2 has a fast turnaround time and can be easily run to equilibrium, climate drift is not a problem. The only constraint is that the equilibrium climate state of the coupled ocean-atmosphere model

Fig. 13a-d Geographical distribution of precipitation in $\mathrm{mm} \mathrm{day}^{-1}$ a Model winter; b model summer; c observed winter; d observed summer 

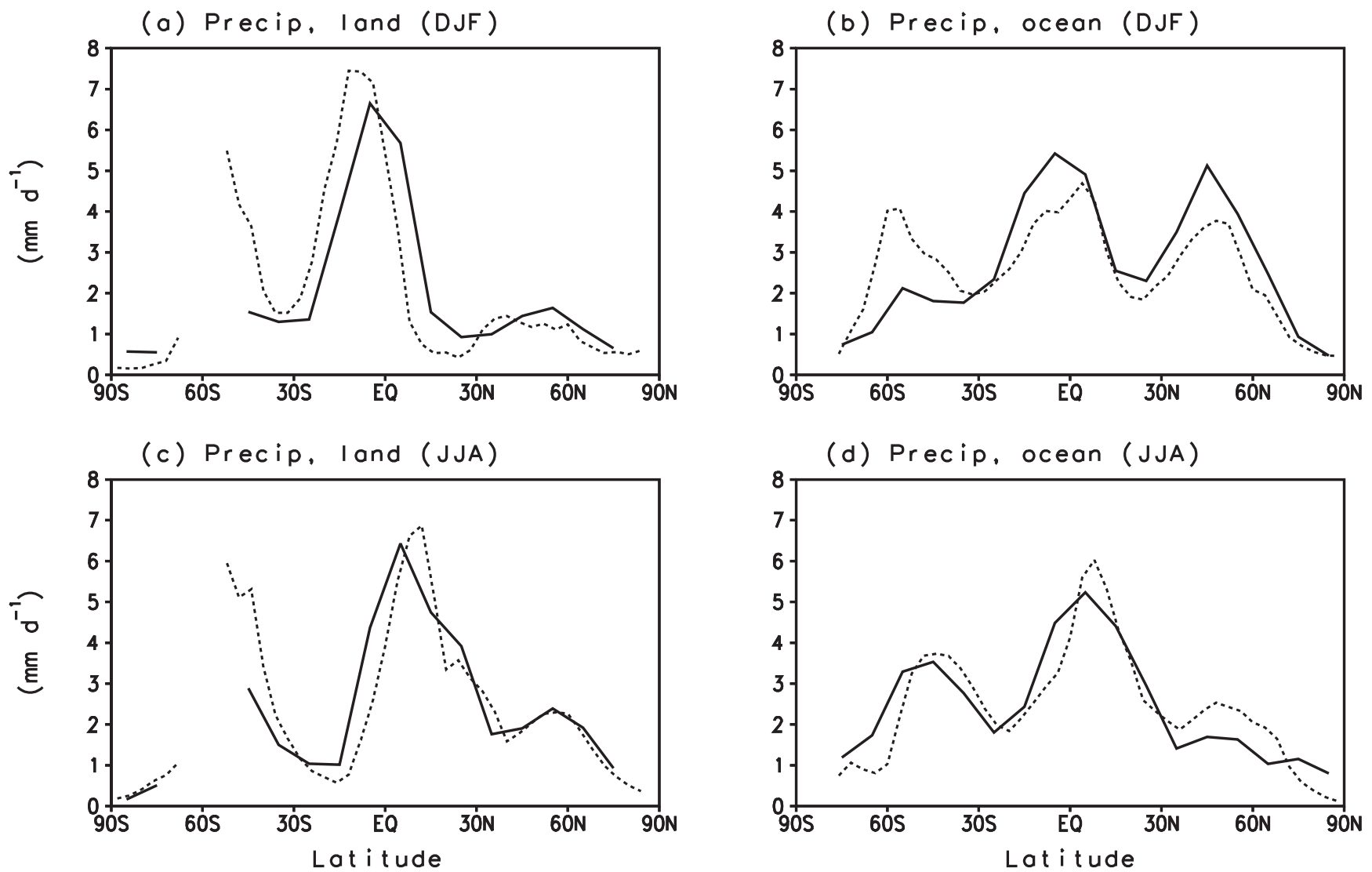

(d) Precip, ocean (JJA)

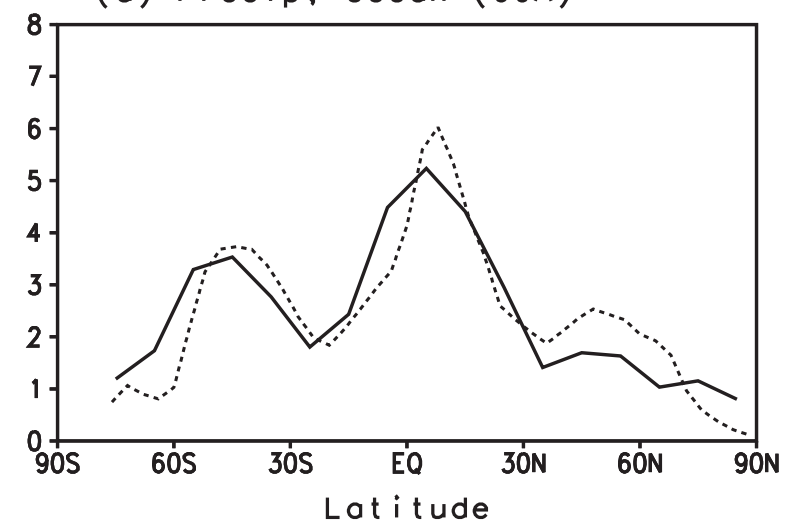

(a) MOD PRC DJF

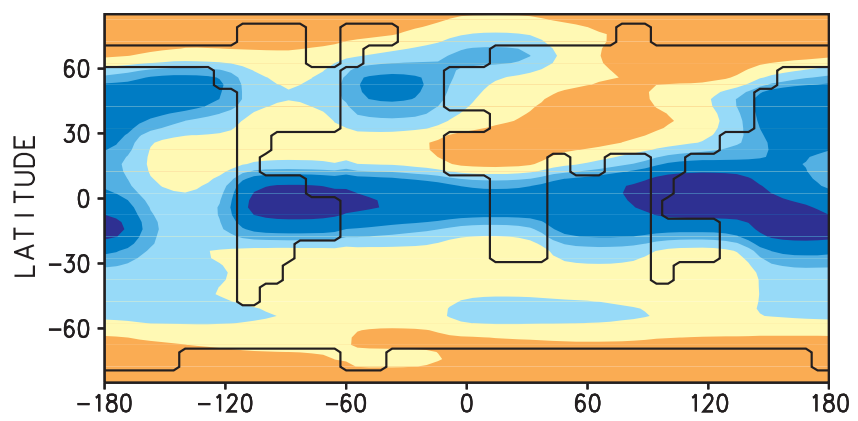

(b) MOD PRC JJA
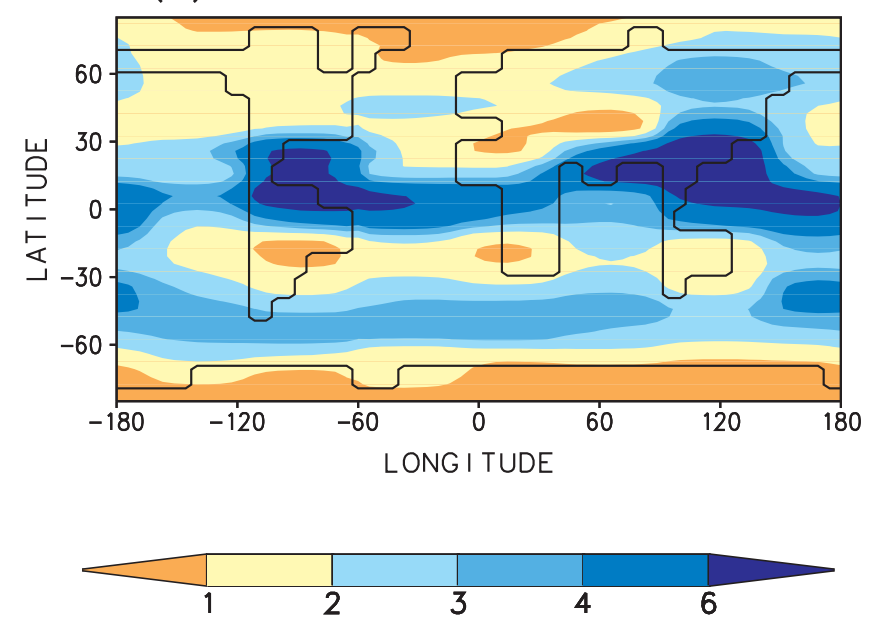

(c) OBS PRC DJF

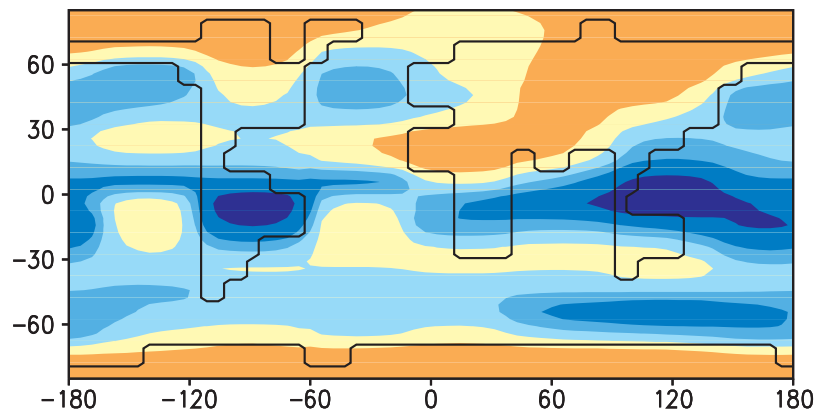

(d) OBS PRC JJA
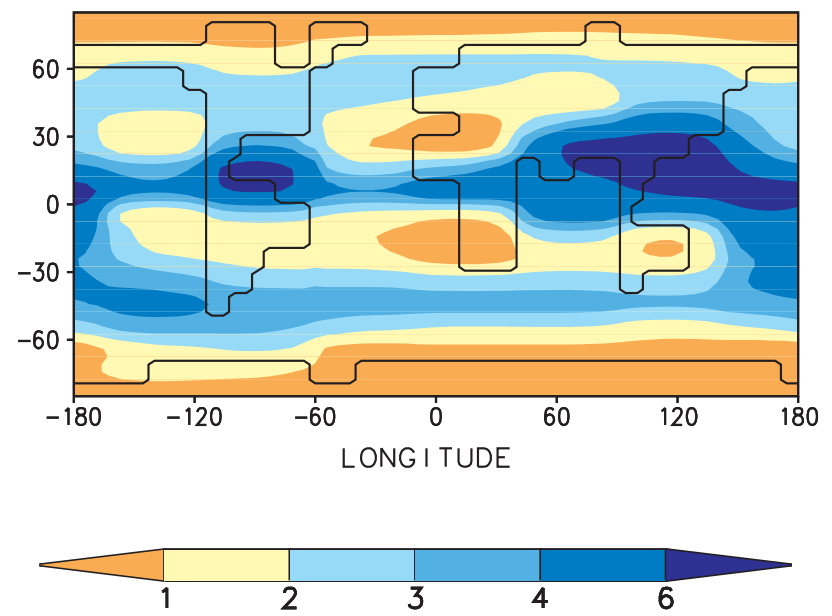


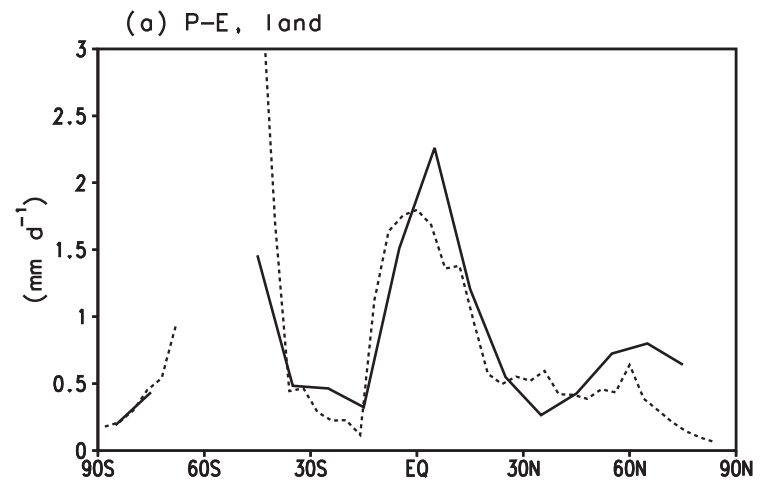

(b) P-E, ocean

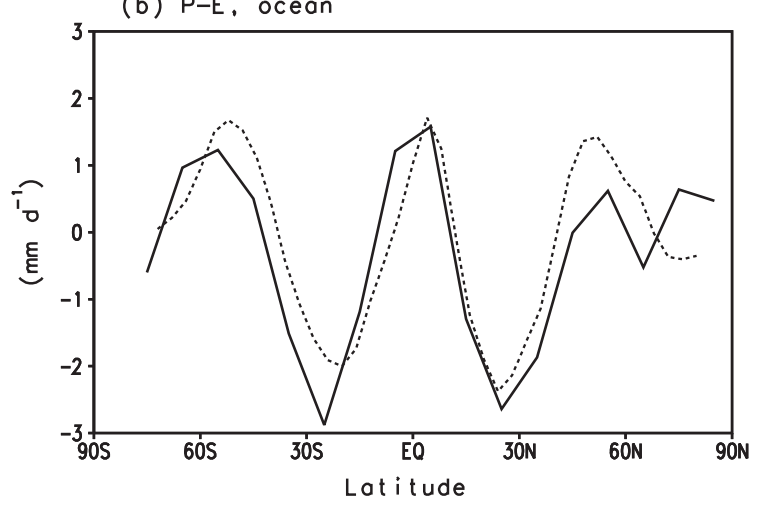

(a) Cloud cover, I and (DJF)

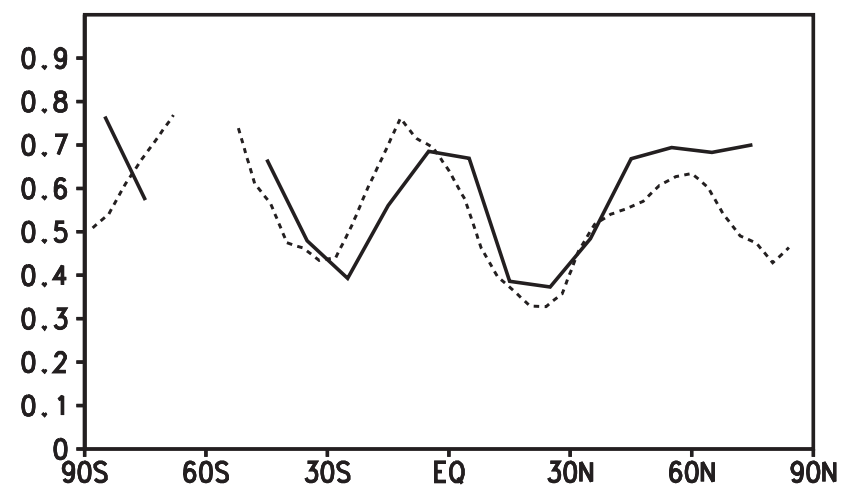

(c) Cloud cover, I and (JJA)

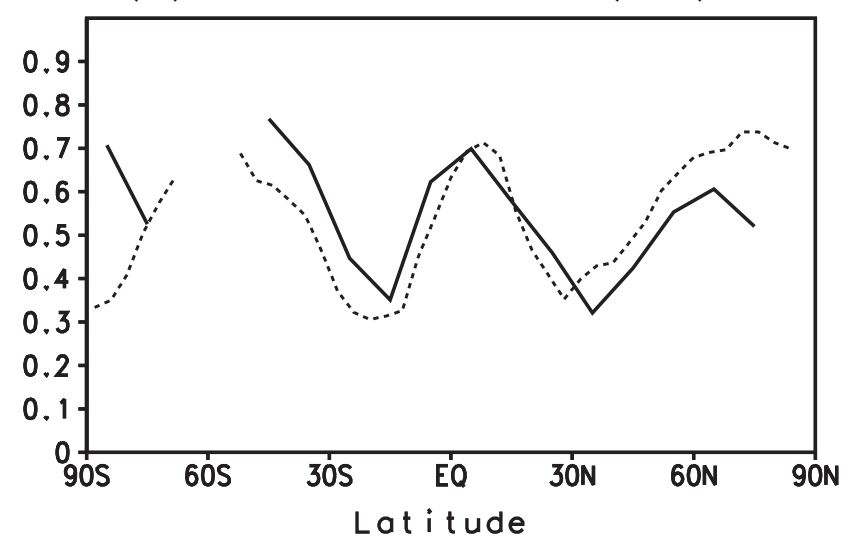

Fig. 14a, b Annual zonally averaged difference between precipitation and evaporation over $\mathbf{a}$ land and $\mathbf{b}$ ocean. Model, solid line, estimates by Baumgartner and Reichel (1975), dashed

has to be as realistic as those obtained separately in atmosphere and ocean with observed boundary conditions. Experiments performed with CLIMBER-2 show that this condition can be met even if the fluxes simulated by the ocean-only model and by the atmosphere-only model are not in perfect agreement. Indeed the meridional heat transport in the ocean, computed in the ocean-only model driven by observed surface conditions (SST, surface salinity and wind stress) and diagnosed from the atmosphere-only model (with prescribed SST and sea ice) are rather different (up to $2 \mathrm{PW}$ in the tropics). After coupling, the oceanic heat transport tends to be close to that simulated in the ocean-only model. This is a consequence of the high sensitivity of surface heat flux to SST in the coupled system $\left(\sim 10 \mathrm{~W} / \mathrm{m}^{2} \mathrm{~K}\right.$, see Rahmstorf and Willebrand 1995); relatively small SST changes strongly affect the surface heat flux while causing only small changes to oceanic heat transport. The freshwater flux in a coupled model, unlike the heat flux, is close to the implied freshwater flux simulated by the atmospheric model. That is to be expected, as the surface freshwater flux is not very sensitive to the ocean climate. Freshwater

(b) Cloud cover, ocean (DJF)

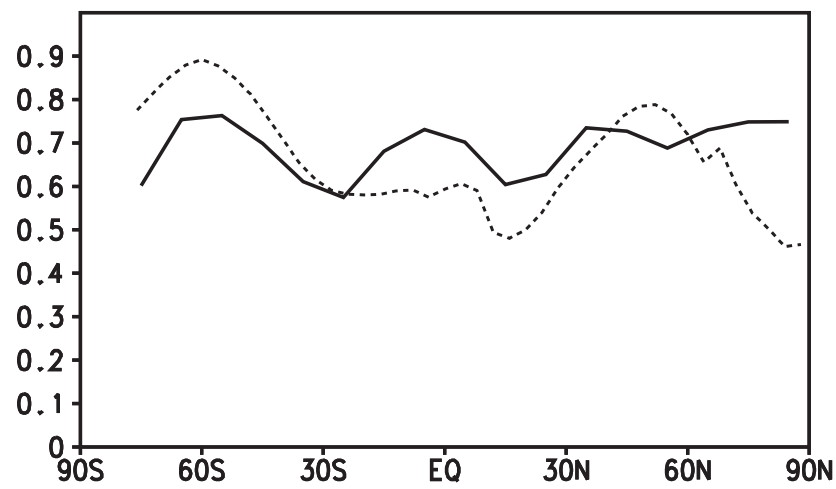

(d) Cloud cover, ocean (JJA)

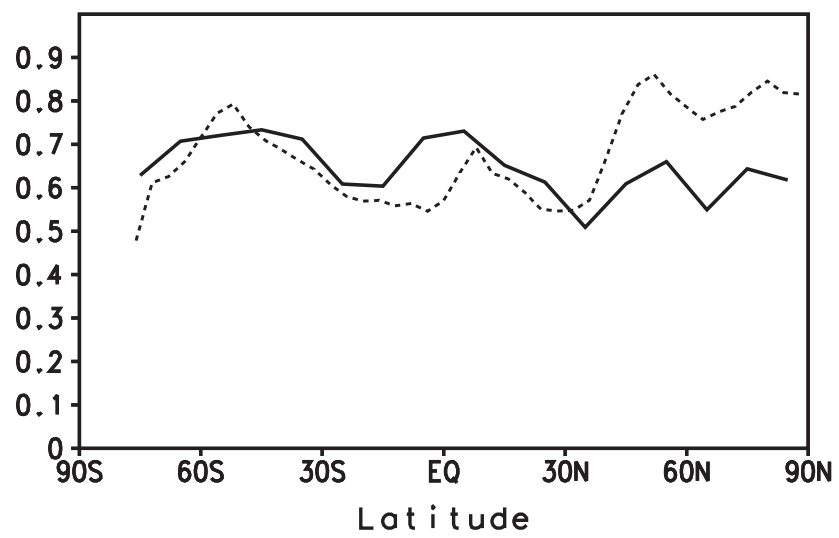

Fig. 15a-d The same as Fig. 10 but for cloudiness 


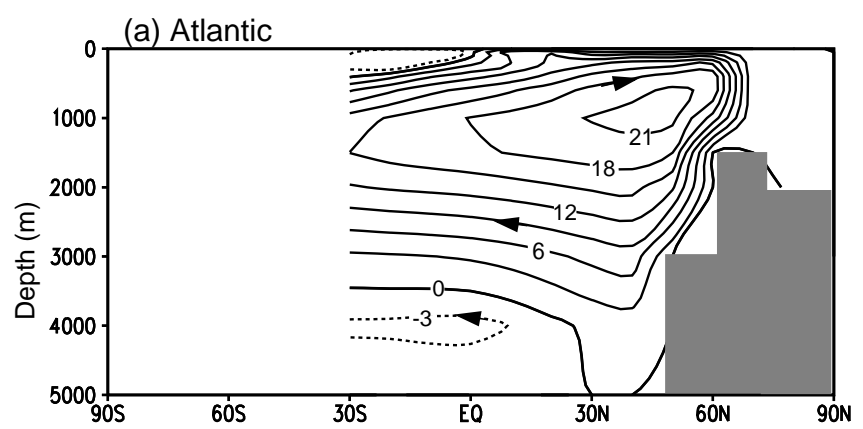

(b) Indo-Pacic

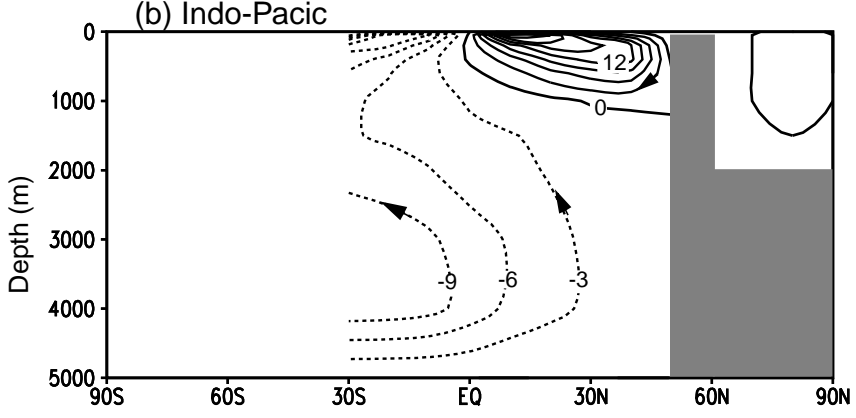

(c) World ocean

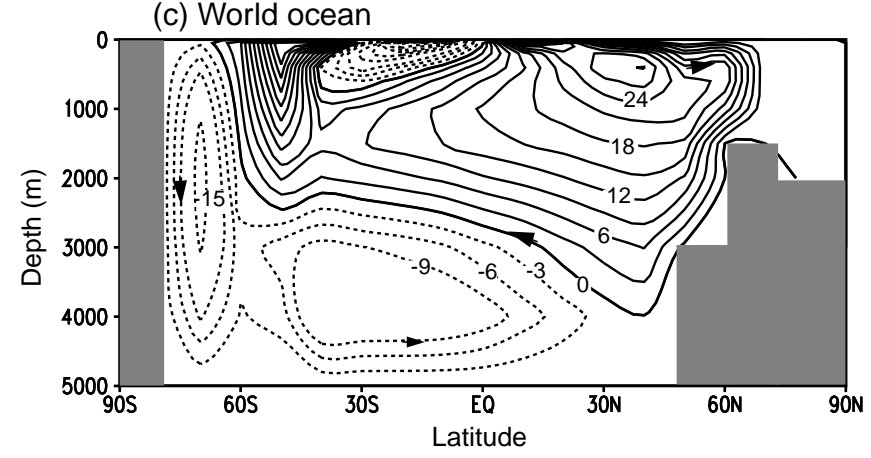

Fig. 16a-c Oceanic overturning stream function in Sv for a Atlantic, b Indo-Pacific, and c World ocean

flux plays a very important role in the stability of the thermohaline circulation. Rahmstorf (1996) has shown that the stability of the thermohaline circulation in the Atlantic depends primarily on an integrated freshwater budget of the Atlantic basin north of $30^{\circ} \mathrm{S}$. Empirical data suggest that this integral flux is about $0.2-0.3 \mathrm{~Sv}$ (net evaporation). The results of our model fall into this interval. If this flux is reduced by only $0.1-0.2 \mathrm{~Sv}$, North Atlantic deep water formation will collapse. Therefore, a realistic freshwater budget of the Atlantic prior to coupling is crucial for a modeling realistic thermohaline circulation.

\section{Present-day climate}

In this section we discuss the performance of the fully coupled climate model for modern climate conditions. "Modern" means hereafter the present-day Earth geography, solar insolation and preindustrial $\mathrm{CO}_{2}$ con- centration $(280 \mathrm{ppm})$. The distribution of potential (no human land-use) vegetation was prescribed. To reach the equilibrium climate state the coupled model was integrated for 5000 years.

\subsection{Atmosphere}

Table 2 shows the partition of the globally averaged annual energy balance in the climate system in comparison with the empirical data of Kiehl and Trenberth (1996). The zonal mean outgoing LWR at the top-ofthe-atmosphere and planetary albedo are compared with ERBE data (Harrison et al. 1990) for winter and summer seasons in Fig. 4. The differences between simulated and observed zonal means for outgoing LWR are within $20 \mathrm{~W} / \mathrm{m}^{2}$, an error typical for atmospheric GCMs. The spatial-temporal variability of the planetary albedo is also reproduced realistically. The resulting annual energy balance at the top of the atmosphere, presented in Fig. 5 in the form of meridional heat transport in the ocean-atmosphere system, agrees well with ERBE data.

Zonally averaged sea level pressure (SLP) for winter and summer (Fig. 6) shows good agreement with observed data, apart from the model's overestimate of SLP over the Southern Ocean. The spatial distribution of SLP (shown in Fig. 7) in the model by and large agrees with data in respect of the large-scale patterns of SLP for both seasons, including positions and absolute values of the stationary high and low-pressure systems in the subtropics and mid-latitudes. Some features of the zonally averaged atmospheric circulation are shown in Fig. 8. The model captures the positions and amplitudes of jet streams and tropical easterlies reasonably well. As described in Sect. 3.2, the "topology" of the zonally averaged atmospheric meridional mass transport in prescribed in the model (see Eqs. 18-22). Even so the model has sufficient degrees of freedom to predict the intensity and latitudinal location of each atmospheric cell and their seasonal variability. Figure 8 clearly shows that the model circulation agrees well with the observed data (e.g., Peixoto and Oort 1992) apart from the intensity of the southern Hadley cell in austral summer being too strong. The model yields a realistic structure of zonally averaged vertical velocity, which is important for a realistic representation of global precipitation patterns. Moreover the model captures the major features of the 3-dimensional circulation, including the monsoon circulation. Even in the tropics, where the model dynamics is described in a very simple way by fixing the Coriolis parameter, the Walker circulation is reproduced. In contrast, the orographic effects are very weak in the model due to its low horizontal resolution. Zonally averaged surface wind speed and westerly wind stress are depicted in Fig. 9 in comparison with empirical data (GUACA 1993; Hellerman and Rosenstein 1983). The model predicts the spatial and temporal variability of surface wind speed fairly well. Since a major part of surface wind outside the tropics is explained by synoptic 
(a) Atlantic meridionol heot flux

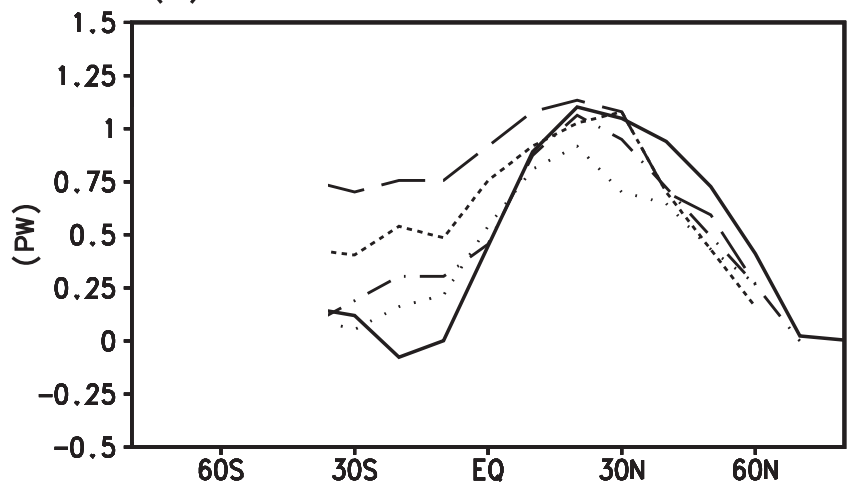

(b) Global meridional heat f Iux

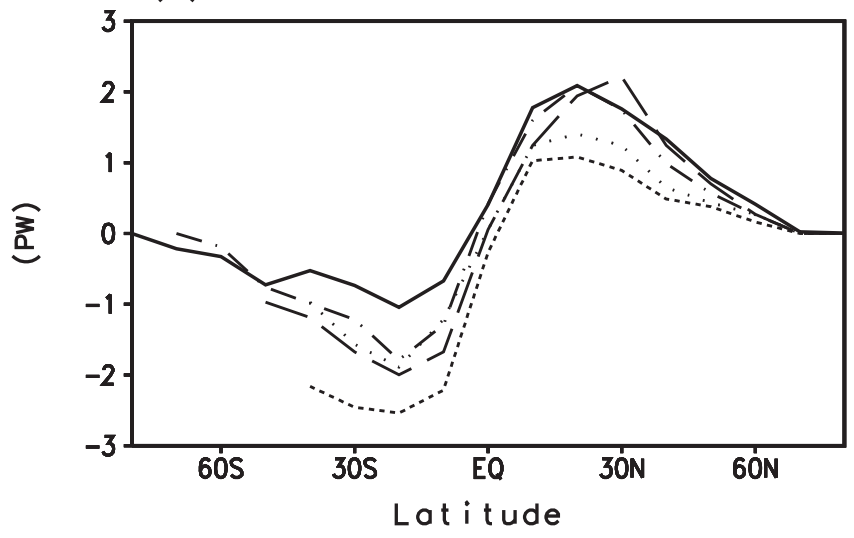

Fig. 17a, b Meridional heat and $\mathbf{c}, \mathbf{d}$ freshwater transport in the a, $\mathbf{c}$ Atlantic and b, d World Ocean. Model, solid line. Empirical estimates for heat transport: Hastenrath (1982), long-dashed line; Talley (1984), short-dashed line; Hsiung (1985), dashed-dotted line; Trenberth and

variability, this shows the performance of the model in reproducing ensemble-averaged characteristics.

The zonally averaged temperatures over continents and oceans, shown in Fig. 10, are in both seasons in good agreement with observation. The annual, globally averaged standard deviation of simulated monthly temperatures from observed is about $3 \mathrm{~K}$. The highest errors in monthly surface air temperature occur at high latitudes while for most grid points in middle and lower latitudes the absolute errors in the monthly temperature do not exceed $4 \mathrm{~K}$ during the whole year. The difference between the zonal mean of model and observed (GUACA 1993) atmospheric temperatures is shown in Fig. 11. The troposphere in the model is too cold with typical biases in the upper troposphere of about 2-4 K. The largest errors occur in the high latitudes in winter. The tropical stratosphere is too warm. The latter is a consequence of assuming a vertically isothermal stratosphere. In general the patterns of the model biases are similar to those typical for many atmospheric GCMs; it also has to be kept in mind that our results represent a coupled equilibrium climate without flux adjustment.

Realistic simulation of the hydrological cycle is a challenging task for a relatively simple and low resolution model like CLIMBER-2, since precipitation has (c) Atlontic meridional freshwoter flux

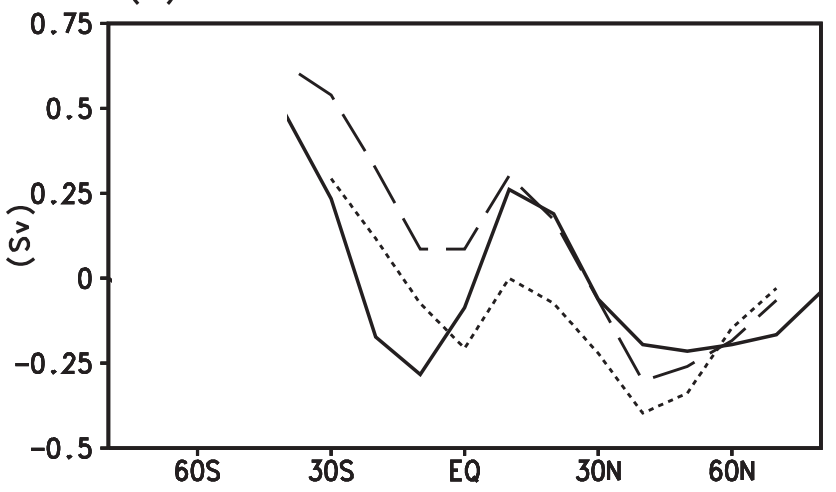

(d) Global meridional freshwater flux

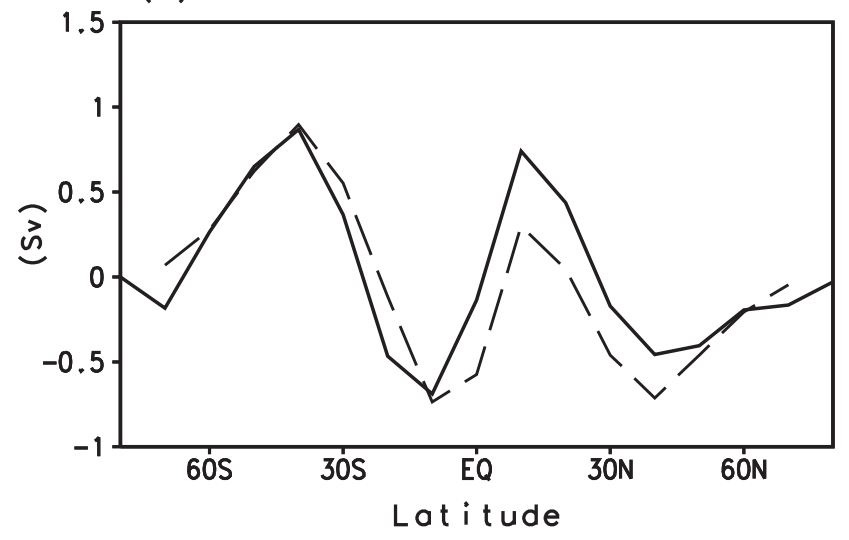

Solomon (1994), dotted line. Empirical estimates for freshwater transport: Baumgartner and Reichel (1975), long-dashed line; Schiller (1995), short-dashed line

very strong spatial and temporal variability. Even climate fields of precipitation are extremely inhomogeneous within the area covered by the model grid cells. In this light, the agreement of simulated precipitation with estimates (Jaeger 1976: Figs. 12, 13) is surprisingly good, although the model has some deficiencies. Zonal mean precipitation (Fig. 12) is underestimated in summer over mid-latitude oceans in both hemispheres and overestimated during winter in the Northern Hemisphere. At the same time the annual averaged precipitation (as well as evaporation) agree well with empirical data both over continents and oceans. By and large, the spatial distribution of precipitation (Fig. 13) is captured correctly. The model predicts maxima of precipitation over the Western Pacific, South and Central America, following seasonal shifts of the intertropical convergence zone. It also shows summer monsoon precipitation over Southern and Eastern Asia, as well as the subtropical belt of low precipitation in the Southern Hemisphere, with strong longitudinal variability of precipitation in the northern subtropical belt. The zonal and annual mean difference between precipitation and evaporation over land and ocean is shown in Fig. 14. For the land this difference represents the zonally averaged runoff, which agrees well with empirical data except for the latitudes 


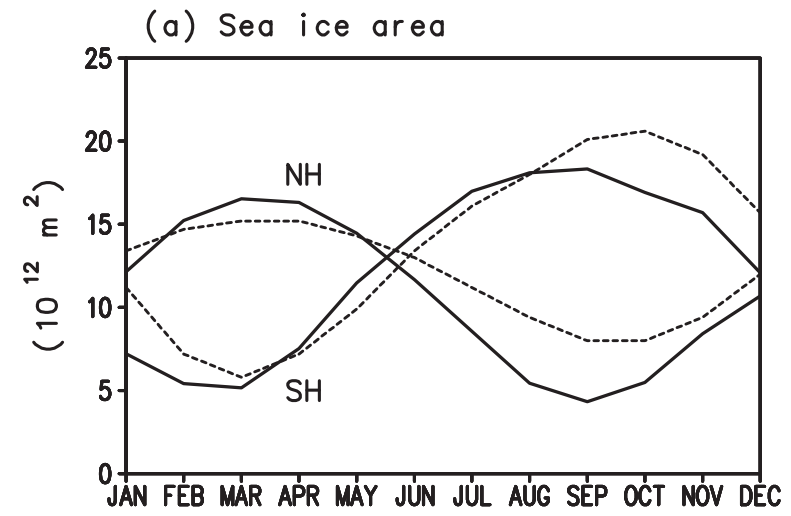

(b) Snow area in $\mathrm{NH}$

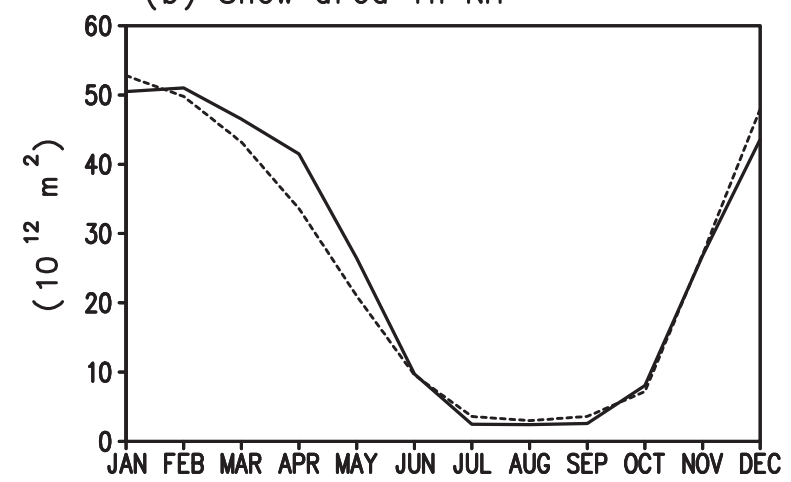

Fig. 18a, b Seasonal cycle of a sea-ice area in the $\mathrm{NH}$ and $\mathrm{SH}$ and b snow area in NH. Model, solid line, observed data, dashed line

$30-40^{\circ} \mathrm{S}$, where the area of continents is small. Global annual runoff in the model is $40 \cdot 10^{12} \mathrm{~m}^{3} \mathrm{y}^{-1}$, which is close to empirical estimates. Freshwater flux over the oceans also agrees well with empirical data except for the high latitudes. Zonal mean cloudiness over ocean and continents (Fig. 15) shows that the model captures the spatio-temporal variability of the total cloud fraction, apart from the model underestimating the cloud fraction in summer-time over oceans in the Northern Hemisphere. Global annual cloud fraction in the model is 0.62 , within the range of empirical estimates.

\subsection{Ocean}

Numerous experiments with zonally averaged multibasin ocean models have demonstrated their ability to reproduce major features of ocean climate reasonably well when driven by prescribed present-day boundary conditions (e.g., Stocker et al. 1992; Fichefet and Hovine 1993), although the stimulated vertical structure of temperature and salinity in this kind of model has some typical biases (e.g., too flat a thermocline in the tropics). The ocean in our model is driven by simulated (uncorrected) seasonal fluxes of momentum, heat and freshwater. The vertical overturning stream function for Atlantic and combined Indo-Pacific and global oceans are shown in Fig. 16. They are fairly realistic and similar to results of oceanic GCM simulations, (e.g., Rahmstorf and England 1997) with respect to the intensity of the Atlantic conveyor belt (about $21 \mathrm{~Sv}$ ), the penetration of Antarctic bottom water into the Northern Atlantic, and the circulation in the Pacific and Indian oceans with northward flow near the bottom and southward return flow between 2 and $4 \mathrm{~km}$ depth.

The model predicts a realistic spatial distribution of SST and a correct averaged vertical temperature profile, but in the thermocline it reveals the deficiencies mentioned. The model also captures major features of the salinity distribution in the ocean (including the tongue of Antarctic intermediate water at a depth of about $1 \mathrm{~km}$, see Ganopolski et al. 1998a, their Fig. 3), but underestimates the amplitude of latitudinal variations. Meridional heat and freshwater transports for the Atlantic and global oceans are shown in Fig. 17. The model predicts meridional transport in the Atlantic and globally close to the empirical estimates in the Northern Hemisphere, while it underestimates southward transport in the Southern Hemisphere. The latter can be explained by the lack of meridional heat transport due to the horizontal gyre circulation. Meridional freshwater flux (as mentioned) is primarily defined by the atmospheric model. The stimulated transport agrees well with empirical estimates.

\subsection{Cryosphere}

Modeling of realistic sea ice and snow cover is an equally difficult and important problem for coupled climate models, because of the strong positive ice- and snowalbedo feedback. The seasonal cycle of sea-ice cover is shown in Fig. 18a in comparison with observed data of Rayner et al. (1995). In the Northern Hemisphere the model performs well, in the Southern Hemisphere it predicts a too rapid growth of sea ice in autumn. The typical thickness of sea ice is $2-3 \mathrm{~m}$ in the Arctic and 1-2 $\mathrm{m}$ in the Southern Ocean. The seasonal cycle of the snow covered area in the Northern Hemisphere (Fig. 18b) agrees well with data of Peixoto and Oort (1992).

\section{Conclusions}

We have described the major features of the climate system model of intermediate complexity, CLIMBER-2, and its performance for present climate conditions. The key element of the model is a 2.5-dimensional statisticaldynamical atmosphere model, which, despite of its simplicity and low spatial resolution, simulates the seasonal evolution of a comprehensive set of climatic characteristics. The use of simplified dynamical equations and the parametrization of the vertical structure of the atmosphere allow a large time step of integration (compared to GCMs), which gives the model the fast turnaround time required for the study of climate system 
dynamics. Comparison of the coupled climate model with empirical data shows that it is able to capture many features of the atmosphere and the ocean climate fairly realistically. In general, the performance of the model is comparable to that of coupled GCMs, but that should be viewed in the context the CLIMBER-2 belongs to a different model class. CLIMBER-2 is not intended to compete with comprehensive models; it rather represents a complementary approach allowing us to extend the range of climate system analysis due to lower computational cost.

Realistic simulation of present climate is an important part of the validation of any climate model, but this is the only first step. The credibility of any new climate model increases substantially if it is able to reproduce the robust features of the response to different types of forcings found in other comprehensive models. This part of validation of our model will be presented in part II of this study, where the model response to changes in solar insolation, carbon dioxide, freshwater flux and land cover is compared with the results of GCMs. The rapidly growing amount and quality of paleodata makes possible a third type of model validation: simulation of paleoclimates and comparison with empirical data. In Ganopolski et al. (1998a, b) we have shown that CLIMBER-2 successfully reproduces many aspects of the climates of last glacial maximum (21 000 years BP) and mid-Holocene (6000 years BP). This type of validation is being extended by performing not only different time-slice experiments but also simulation of the transient response of the climate system to orbital forcing on time scales up to 100000 years.

\section{References}

Alcamo J, Kreileman GJJ, Krol MS, Zuidema G (1994) Modelling the global society-biosphere-climate system. Part I: model description and testing. Water Air Soil Polut 76: 1-35

Baumgartner A, Reichel E (1975) The world water balance. Elsevier, Amsterdam, 179 pp

Berger A, Fichefet T, Gallee H, Tricot Ch, van Ypersele JP (1992) Entering the glaciation with a 2-D coupled climate model. Quat Sci Rev 11: 481-493

Blinova EN (1958) On a theory of nonzonal circulation of the Earth's atmosphere. Proc Institute of Atmospheric Physics Rep 2. Academy of Sciences of the USSR Publishing House, Moscow: 5-22 (in Russian)

Bryan K, Lewis LJ (1979) A water mass model of the World Ocean. J Geophys Res 85: 2503-2517

Brovkin V, Ganopolski A, Svirezhev Y (1997) A continuous climate-vegetation classification for use in climate-biosphere studies. Eco Model 101: 251-261

Burger AP (1958) Scale consideration of planetary motions of the atmosphere. Tellus 10: 195-205

Cao M, Woodward FI (1998) Dynamic responses of terrestrial ecosystem carbon cycling to global climate change. Nature 393: 249-252

Claussen M, Gayler V (1997) The greening of Sahara during the mid-Holocene: results of an interactive atmosphere - biome model. Global Ecol Biogeogr Lett 6: 369-377

Dickinson RE, Henderson-Sellers A, Kennedy PJ, Wilson MF (1986) Biosphere-Atmosphere Transfer Scheme (BATS) for the
NCAR CCM, NCAR/TN-275-STR, National Center for Atmospheric Research, Boulder, Colo, USA, 69 pp

Dushkin PK, Lomonosov EG, Lunin YuN (1960) A test of numerical method of humidity, cloudiness and precipitation forecast using a computer. Meteorol Hydrol 12: 3-12

Feigelson EM, Ginzburg AS, Krasnokutskaya LD, Petoukhov VK (1975) Effects of clouds on the radiative heat exchange in the atmosphere. Geofis Intern 15: 293-326

Fichefet T, Hovine S (1993) The glacial ocean: a study with a zonally averaged, three-basin ocean circulation model. In: Peltier WR (ed) Ice in the climate system. NATO ASI Series I 12: 433-458

Foley JA, Levis S, Prentice IC, Pollard D, Thompson SL (1998) Coupling dynamic models of climate and vegetation, Global Change Biol (in press)

Ganopolski A, Rahmstorf S, Petoukhov V, Claussen M (1998a) Simulation of modern and glacial climates with a coupled model of intermediate complexity. Nature 391: 351-356

Ganopolski A, Kubatzki C, Claussen M, Brovkin V, Petoukhov V (1998b) The influence of vegetation-atmosphere-ocean interaction on climate during mid-Holocene. Science 280: 1916-1919

Gleckler PJ, Randall DA, Boer G, Colman R, Dix M, Galin V, Helfend M, Kiehl J, Kitoh A, Lau W, Liang X-Z, Lykossov V, McAvaney B, Miyakoda K, Planton S, Stern W (1995) Cloudradiative effects on implied oceanic energy transports as simulated by atmospheric general circulation models. Geophys Res Lett 22: 791-794

Gorchakova IA, Leont'eva EN (1991) Approximate calculations of the integral fluxes of longwave radiation. Izvestiya AS USSR, Atmos Ocean Phys 27: 165-171

GUACA (Global upper air climatic atlas) (1993) NCDC, NOAA

Gulev SK, Zveryaev II, Mokhov II (1991) Tropospheric lapse rate in dependence on surface temperature. Izvestiya AS USSR, Atmos Ocean Phys 27: 419-430

Hansen J, Russell G, Rind D, Stone P, Lacis A, Lebedeff S, Ruedy R, Travis L (1983) Efficient three-dimensional global models for climate studies: Models I and II. Mon Weather Rev 111: 609-662

Harrison EP, Minnis P, Barkstrom BP, Ramanathan V, Cess RD, Gibson GG (1990) Seasonal variation of cloud radiative forcing derived from the Earth Radiation Budget Experiment. J Geophys Res 95: 18 687-18 703

Harvey LD (1989) Milankovitch forcing, vegetation feedback, and North Atlantic deep water formation. J Clim 8: 800-815

Hasselmann K (1976) Stochastic models. I. Theory. Tellus 28: 473-485

Hastenrath S (1982) On meridional heat transport in the world ocean. J Phys Oceanogr 12: 922-927

Held IM, Hou AY (1980) Nonlinear axially symmetric circulations in a nearly inviscid atmosphere. J Atmos Sci 37: 515-533

Held IM, Larichev VD (1996) A scaling theory for horizontally homogeneous, baroclinically unstable flow on a beta plane. J Atmos Sci 53: 946-952

Hellerman S, Rosenstein M (1983) Normal monthly wind stress over the World Ocean with error estimates. J Phys Oceanogr 13: $1093-1104$

Houghton JT, Meira Filho LG, Callander BA, Harris N, Kattenberg A, Maskell K (1996) Climate change 1995. The science of climate change. Cambridge University Press, Cambridge, UK, $572 \mathrm{pp}$

Hsiung J (1985) Estimates of global oceanic meridional heat transport. J Phys Oceanogr 15: 1405-1413

Jaeger L (1976) Monatskarten des Niederschlags für die ganze Erde. Ber Deutsche Wetterdienstes 18(139) 38 pp

Kiehl JT, Trenberth KE (1996) Earth's annual global mean energy budget. Bull Am Meteorol Soc 78: 197-208

Lacis AA, Hansen JE (1974) A parametrization for the absorption of solar radiation in the Earth's atmosphere. J Atmos Sci 31: 238-248

Lemke P (1977) Stochastic climate models. Part 3. Application to zonally averaged models. Tellus 29: 387-392

Lindzen RS, Hou AY (1988) Hadley circulations for zonally averaged heating centered off the equator. J Atmos Sci 45: 2416-2427 
Lorenz EN (1955) Available potential energy and the maintenance of the general circulation. Tellus 7: 157-167

Melillo JM, McGuire AD, Kiclighter DW, Moore III B, Vorosmarty CJ, Schloss AL (1993) Global climate change and terrestrial net primary production. Nature 363: 234-240

Mitchell JM (1976) An overview of climatic variability and its causal mechanisms. Quat Res 6: 481-493

Mokhov II, Petoukhov VK (1978) Parametrization of outgoing flux of longwave radiation for climate models. Preprint IAP AS USSR, Moscow, $34 \mathrm{pp}$ (in Russian)

de Noblet NI, Prentice IC, Joussaume S, Texier D, Botta A, Haxeltine A (1996) Possible role of atmosphere-biosphere interaction in triggering the last glaciation. Geophys Res Lett 23: 3191-3194

Oort AH, Rasmusson EM (1971) Atmospheric circulation statistics. NOAA Prof Pap 5, $323 \mathrm{pp}$

Peixoto J, Oort A (1992) Physics of climate. American Institute of Physics, New York, 520 pp

Petoukhov VK (1976) Zonally averaged model of heat and moisture exchange in the atmosphere-underlying layer system. Izvestiya AS USSR, Atmos Ocean Phys 11: 1130-1142

Petoukhov VK (1982) Two mechanisms of temperature oscillations in a thermodynamical model of the troposphere-stratosphere system. Izvestiya AS USSR, Atmos Ocean Phys 18: 126-137

Petoukhov VK, Ganopolski AV (1994) A set of climate models for integrated modelling of climate change impacts. Part II: A 2.5dimensional dynamical-statistical climate model (2.5-DSCM). IIASA WP-94-39, International Institute for Applied System Analysis, Laxenburg, Austria, $96 \mathrm{pp}$

Rahmstorf S (1996) On the freshwater forcing and transport of the Atlantic thermohaline circulation. Clim Dyn 12: 799-811

Rahmstorf S, England MH (1997) Influence of Southern Hemisphere wind on North Atlantic deep water flow. J Phys Oceanogr 27: 2040-2054

Rahmstorf S, Willebrand J (1995) The role of temperature feedback in stabilizing the thermohaline circulation. J Phys Oceanogr 25: 787-805

Rayner NA, Foland CK, Parker DE, Horton EB (1995) A new global sea-ice and sea surface temperature (GISST) data set for 1903-1994 for forcing climate models. Hadley Centre Internal Note 69. UK Meteorological Office, Bracknell, UK

Saltzman B (1978) A survey of statistical-dynamical models of the terrestrial climate. Adv Geophys 20: 183-304
Saltzman B, Vernekar AD (1972) Global equilibrium solutions for the zonally averaged macroclimate. J Geophys Res 77: 39363945

Sarmiento JL, Le Quere C (1996) Oceanic carbon dioxide uptake in a model of century-scale global warming. Science 274: 13461350

Schiller A (1995) The mean circulation of the Atlantic Ocean north of $30 \mathrm{~S}$ determined with the adjoint method applied to an ocean general circulation model. J Mar Res 53: 453-497

Schneider EK, Lindzen RS (1977) Axially symmetric steady-state models of the basic state for instability and climate studies. Part I. Linearized calculations. J Atmos Sci 34: 263-279

Semtner AJ (1976) A model for the thermodynamic growth of sea ice in numerical investigations of climate. J Phys Oceanogr 6: $379-389$

von Sommerfeld A (1952) Thermodynamik und Statistik. Vorlesungen über Theoretische Physik V. Wiesbaden, $479 \mathrm{pp}$

Stocker TF, Wright DG, Mysak LA (1992) A zonally averaged, coupled ocean-atmosphere model for paleoclimate studies. J Clim 5: 773-797

Stone PH, Yao M-S (1990) Development of a two-dimensional zonally averaged statistical-dynamical model. Part III: the parametrization of the eddy fluxes of heat and moisture. J Clim 3: 726-740

Talley LD (1984) Meridional heat transport in the Pacific Ocean. J Phys Oceanogr 14: 231-241

Trenberth KE, Solomon A (1994) The global heat balance: heat transport in the atmosphere and ocean. Clim Dyn 10: 107-134

Van der Hoven I (1957) Power spectrum of horizontal wind speed in the frequence range from 0.0007 to 900 cycles per hour. J Meteorol 14: 160-164

Vinnichenko NK (1970) The kinetic energy spectrum in the free atmosphere -1 second to 5 years. Tellus 22: 158-166

Wallace JM, Hobbs PV (1977) Atmospheric science: an introductory survey. Academic Press, New York, $467 \mathrm{pp}$

Williams GP, Davis DR (1965) A mean motion model of general circulation. J R Meteorol Soc 91: 471-489

Xiao X, Kicklighter DW, Melillo JM, McGuire AD, Stone PH, Sokolov AP (1997) Linking a global terrestrial biogeochemical model and a 2-dimensional climate model: implications for the global carbon budget. Tellus 49B: 18-37

Yamamoto G, Tanaka M (1972) Increase of global albedo due to air pollution. J Atmos Sci 29: 1405-1412 